\title{
Test of a Weather-Adaptive Dual-Resolution Hybrid Warn-on-Forecast Analysis and Forecast System for Several Severe Weather Events
}

\author{
YUNHENG WANG \\ Cooperate Institute for Mesoscale Meteorological Studies, University of Oklahoma, and \\ NOAA/National Severe Storms Laboratory, Norman, Oklahoma \\ JIDONG GAO \\ NOAA/National Severe Storms Laboratory, Norman, Oklahoma
}

\author{
PATRICK S. SKinner, Kent KNOPFMEIER, ThOMAs Jones, AND GERRY CREAGER \\ Cooperate Institute for Mesoscale Meteorological Studies, University of Oklahoma, and \\ NOAA/National Severe Storms Laboratory, Norman, Oklahoma \\ PAMEla L. Heiselman AND LOUIS J. WiCKeR \\ NOAA/National Severe Storms Laboratory, Norman, Oklahoma
}

(Manuscript received 9 April 2019, in final form 3 September 2019)

\begin{abstract}
A real-time, weather adaptive, dual-resolution, hybrid Warn-on-Forecast (WoF) analysis and forecast system using the WRF-ARW forecast model has been developed and implemented. The system includes two components, an ensemble analysis and forecast component, and a deterministic hybrid three-dimensional ensemble-variational (3DEnVAR) analysis and forecast component. The goal of the system is to provide ondemand, ensemble-based, and physically consistent gridded analysis and forecast products to forecasters for making warning decisions. Both components, the WRF-DART system with 36 ensemble members and the hybrid 3DEnVAR system, assimilate radar data, satellite-retrieved cloud water path, and surface observations at 15-min intervals with dual-resolution capability. In the current hybrid configuration, one-way coupling of the two analysis systems is performed: ensemble covariances derived from the WRF-DART system are incorporated into the hybrid 3DEnVAR system with each data assimilation (DA) cycle. This study examines deterministic, 3-h forecasts launched from the hybrid 3DEnVAR analyses every $30 \mathrm{~min}$ for three severe weather events in 2017. The performance of the deterministic component is evaluated for four configurations: dual-resolution coupling, single-resolution coupling, forecasts initialized using a cloud analysis for reflectivity assimilation, and forecasts initialized from the WRF-DART ensemble mean. Quantitative and subjective evaluation of composite reflectivity and updraft helicity (UH) swath forecasts for the three events indicate that the dual-resolution strategy without the cloud analysis performs best among the four configurations and provides the most realistic prediction of reflectivity patterns and UH tracks.
\end{abstract}

\section{Introduction}

Increasing lead times for severe thunderstorm, tornado, and flash flood warnings is the mission of NOAA's Warnon-Forecast $(\mathrm{WoF})$ project, which was funded in order to reduce the loss of life and property, injury, and economic costs of high-impact weather. This goal is attainable owing to advances in convection-allowing numerical weather

Corresponding author: Dr. Jidong Gao, jidong.gao@noaa.gov prediction (NWP; Stensrud et al. 2009, 2013). Convectionallowing NWP must include an explicit microphysics scheme and run with small horizontal grid spacing (typically $<4 \mathrm{~km}$ ). The nonhydrostatic Advanced Research version of the Weather Research and Forecasting (WRF-ARW) Model (Skamarock et al. 2008) developed at the National Center for Atmospheric Research (NCAR) is widely used for this purpose.

Another important component for improving convectivescale forecasts is the development of convective-scale data 
assimilation (DA) schemes. These DA schemes can take advantage of dense, remotely sensed observations that can sample the internal structure of storms. In particular the Weather Surveillance Radar-1988 Doppler (WSR-88D) and the Geostationary Operational Environmental Satellite R-series (GOES-R) are able to generate observations of convection having very fine temporal and spatial scales. These high-resolution observations should be assimilated into the convectionallowing NWP model in real time with high-frequency cycles $(5-15 \mathrm{~min})$ to provide an accurate analysis of convective storms. To meet these requirements, Gao et al. (2013) developed an efficient, real-time, weatheradaptive three-dimensional variational (3DVAR) analysis system for the WoF project that utilizes a moveable analysis domain and assimilates radar observations using 3DVAR (Gao et al. 1999, 2002, 2004; Ge et al. 2010, 2012; $\mathrm{Hu}$ et al. 2006a,b; Stensrud and Gao 2010; Schenkman et al. 2011). Some key features of the analysis system include: 1) incorporating radar observations from multiple WSR-88Ds with the North American Mesoscale model (Janjić et al. 2003) forecast product as the background field for the analysis, 2) real-time analysis and detection of hazardous weather events at small horizontal grid spacing $(1 \mathrm{~km})$ with high cycling frequency $(5 \mathrm{~min})$, and 3 ) the capability to identify strong midlevel circulations embedded in thunderstorms (Gao et al. 2013).

To assess the potential value of the weather-adaptive, real-time analysis system to warning operations, it was formally tested and evaluated by forecasters who participated in the NOAA Hazardous Weather Testbed (HWT) spring experiments from 2011 to 2013. During this period, many severe weather events were successfully detected and analyzed automatically by this 3DVAR system (Gao et al. 2013; Smith et al. 2014; Calhoun et al. 2014). The analyzed storm structures not only matched quite well with synthesized reflectivity fields from multiple radars, but the most intense storms corresponded with the location and time of the National Weather Service (NWS) local storm reports. While the system was able to accurately analyze convective storms, utilizing these analyses for initializing a convectionallowing NWP model remains a significant challenge because WSR-88D radars only observe radial velocity and reflectivity, and the 3DVAR system has limited ability to retrieve unobserved model variables from these radar data alone.

To properly initialize a convection-allowing NWP model, the Advanced Regional Prediction System (ARPS; Xue et al. 2000, 2001, 2003) also implemented the above 3DVAR system together with a complex cloud analysis package (Albers et al. 1996; Zhang et al. 1998; Brewster et al. 2005; Hu et al. 2006a,b). The combined system produced promising forecasts for a tornadic supercell occurring 28 March 2000 near Fort Worth, Texas, with accurate forecasts of individual thunderstorm cells provided with $2-3 \mathrm{~h}$ of lead time. Schenkman et al. (2011) applied the same 3DVAR system/cloud analysis system to an Oklahoma tornadic mesoscale convective system (MCS), utilizing a 1-h assimilation period with 5-min DA cycles to initialize 3-h forecasts. Both qualitative and quantitative comparisons showed good correspondence between observed and model forecast reflectivity fields. However, this study also shows that repeated application of the original 3DVAR plus cloud analysis with high-frequency assimilation cycles $(5 \mathrm{~min})$ led to unrealistic warming in the middle troposphere and over forecast of precipitation (Schenkman et al. 2011).

Improvements to the 3DVAR DA system are expected with implementation of balance constraints for the convective scale (Ge et al. 2012) and/or optimal incorporation of ensemble information (Gao and Stensrud 2014). One of the hybrid DA approaches that combined variational and ensemble Kalman filter (EnKF) techniques was proposed by Lorenc (2003). Many research articles describing hybrid methods have been published in recent years, with most of them focused on synopticscale and mesoscale NWP (e.g., Barker et al. 2012; Buehner 2005; Buehner et al. 2010a,b; Wang et al. 2008, 2013; Zhang et al. 2013; Pu et al. 2016). Only a few studies have been done with convective-scale weather (Gao and Stensrud 2014; Gao et al. 2016; Wang and Wang 2017; Kong et al. 2018). Gao and Stensrud (2014) demonstrated the value of the hybrid method on the convective scale in an observing system simulation experiment (OSSE). Specifically, they showed that incorporation of ensemble-estimated covariances into a variational approach (3DVAR in this case) can significantly improve the accuracy of analyses produced through assimilation of simulated radar data for a supercell storm. This conclusion holds even when a small ensemble (about 5-10 ensemble members) is used and/or the estimated covariance contains severe sampling errors. This kind of frequently updated, numerical model-based, probabilistic, convective-scale analysis and forecast system could be used to support WoF operations. However, the EnKF method used in that study was preliminary without computational optimization, specifically for real-time application (Gao and Stensrud 2014).

Recently, a more advanced ensemble adjustment Kalman filter (EAKF; Anderson 2001) included in the DA Research Testbed software (DART; Anderson and Collins 2007; Anderson et al. 2009) of the National Center for Atmospheric Research (NCAR) was used to 
assimilate WSR-88D observations and satellite-derived cloud water path in a storm-scale ensemble by the National Severe Storms Laboratory (NSSL) WoF team (Jones et al. 2013, 2014, 2016; Wheatley and Stenstrud 2010, 2015; Yussouf et al. 2015). Based on these studies, the NSSL Experimental WoF System for ensembles (NEWS-e) ${ }^{1}$ was developed and tested during the past several years. To evaluate the capabilities of this system, storm-scale ensemble analyses and forecasts were produced for many severe weather events since 2014 (Wheatley et al. 2015; Jones et al. 2016, 2018; Skinner et al. 2018). Results indicate that for most cases, the ensemble forecasts were able to accurately predict rotational characteristics of supercell thunderstorms, as well as the location and timing of convective storms (Skinner et al. 2018). However, the current NEWS-e real-time settings are only in convection-allowing mode (with 3-km horizontal grid spacing). A reduction in horizontal grid spacing will allow the system to resolve internal storm structures for high-impact weather events in greater detail and offers the potential to improve the system.

As pointed out in Stensrud et al. (2009), it is essential that ensemble forecasts are utilized by WoF to produce robust probabilistic forecast guidance, but relatively large ensembles are generally needed to create a robust pure-ensemble DA system, as shown in Wheatley et al. (2015). However, Gao and Stensrud (2014) demonstrated that relatively small ensembles may be adequate for WoF-type forecasts. Therefore, it is appropriate to test a WoF system that uses a hybrid approach of both the 3DVAR and WRF DART ensemble DA systems. Gao and Xue (2008) and Yang et al. (2009) found that an ensemble of forecasts at lower resolution (LR) can be used to estimate the background error covariance of higher-resolution (HR) analysis. The idea was implemented by the Japan Meteorological Agency recently in its local ensemble transform Kalman filter (LETKF) system in a preoperational environment (Fujita 2010). Indeed, almost all major operational weather prediction centers in the world run two separate systems - a relatively LR ensemble prediction system (EPS) and a single HR model prediction. The HR model run usually provides more detailed deterministic weather information with information on uncertainty provided by the LR ensemble forecasts. Therefore, it is appropriate to develop a dualresolution hybrid ensemble and variational DA and forecast system for convective-scale weather within the WoF strategy.

\footnotetext{
${ }^{1}$ In 2019, the NEWS-e acronym was changed to the Warn-onForecast System (WoFS).
}

In this study we introduce and test a real-time, weather adaptive, dual-resolution hybrid $\mathrm{WoF}$ analysis and forecast system (WoF-AFS). The system includes two components: an EAKF-based ensemble analysis and forecast approach (NEWS-e; Jones et al. 2013, 2014, 2016; Wheatley et al. 2015; Yussouf et al. 2015), and a deterministic, convective-scale, hybrid 3DEnVAR analysis and forecast approach (NEWS-var; Gao and Stensrud 2014; Gao et al. 2016; Wang et al. 2018). Only the deterministic component of the system is examined here though the ensemble approach is also used in all experiment designs. Coupled with hybrid 3DEnVAR analysis, one deterministic, 180 -min-long forecast is launched every $30 \mathrm{~min}$ following high-frequency, dual-resolution DA cycles. To show the improvements on the deterministic component we have made during the past several years, several sensitivity forecast experiments, including forecasts initialized from dual-resolution (DR) coupled DA cycles, single low-resolution (SLR) coupled DA cycles, the WRF-DART ensemble mean, as well as DA cycles that combine cloud analysis and hybrid 3DEnVAR are performed for several 2017 severe weather events with the WoF-AFS. Forecast evaluation is conducted with quantitative metrics and subjective evaluation. The quantitative metrics include the neighborhood equitable threat score (nETS; Gilbert 1884; Clark et al. 2010) and frequency bias for the composite reflectivity that is verified against observations obtained from NSSL Multi-Radar Multi-Sensor System (MRMS; Smith et al. 2016). The subjective comparisons are performed with the NWS local storm reports for the tracks of the updraft helicity (UH) between 2 and $5 \mathrm{~km}$ above ground level (Kain et al. 2008, 2010) and the MRMS observations for reflectivity, respectively.

The rest of this paper is organized as follows. Section 2 provides a brief description of the WoF-AFS. Experiment designs are described in section 3. Experiment results are reported and assessed in section 4 . We conclude in section 5 with a summary and future work.

\section{The description of the WoF analysis and forecast system}

As described in the introduction, the hybrid system includes two components, the NEWS-e and NEWS-var. Both systems use the WRF-ARW, version 3.8.1. The NEWS-e also uses the EAKF within DART. It updates the mean and perturbations of the atmospheric state given a set of observations and their associated error based on a prior estimate of the state's probability distribution (Anderson and Collins 2007). The prior probability distribution is estimated from the statistics of an ensemble, which incorporates flow-dependent covariance 


\section{Flowchart of the Hybrid System}

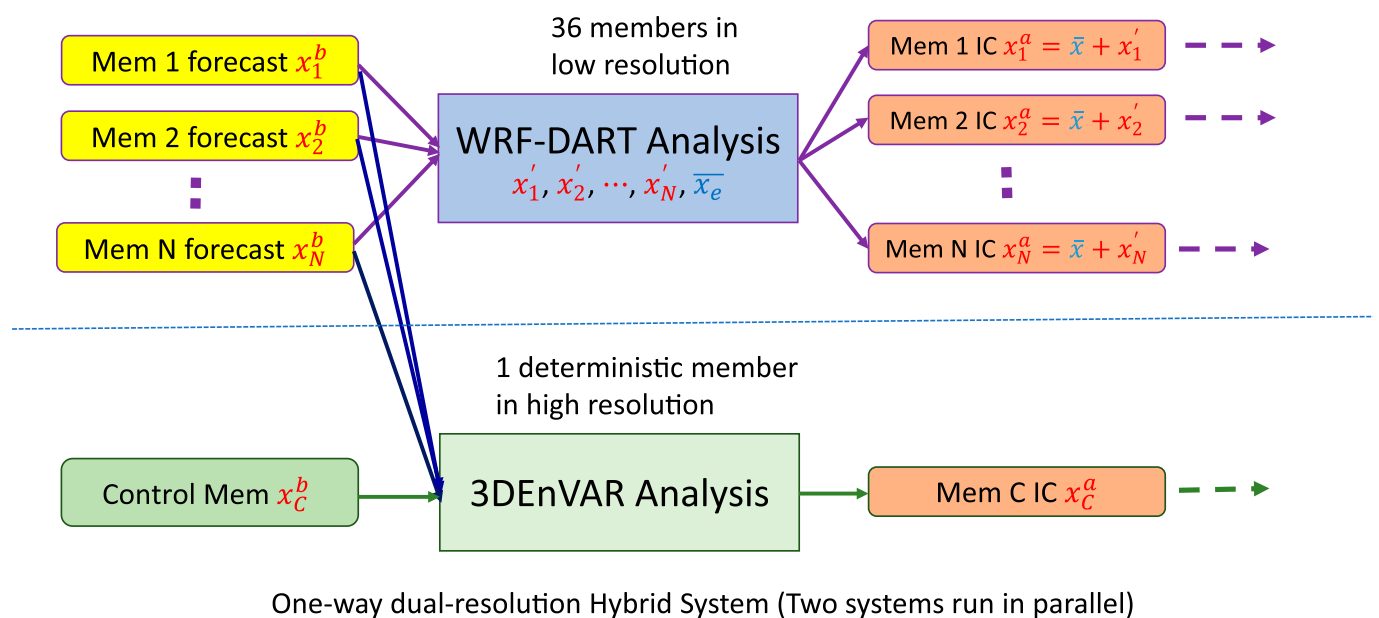

FIG. 1. Workflow of a single data assimilation cycle for the hybrid 3DEnVar and WRF-DART system.

information. Further details on the DART EAKF can be found in Anderson et al. (2009). In the WoF application, 36 ensemble members are used (Wheatley et al. 2015).

The NEWS-var is based on the 3DVAR system designed for radar DA at the convective scale at the Center for Analysis and Prediction of Storms (CAPS; Gao et al. 1999, 2002, 2004; Hu et al. 2006a,b; Ge et al. 2010, 2012) and National Severe Storms Laboratory (NSSL; Stensrud and Gao 2010; Gao and Stensrud 2012; Gao et al. 2013). It applies weak constraints, which are suitable for convective storms in a different manner than that of other 3DVAR systems developed for large-scale applications. In this convective-scale 3DVAR scheme, cross correlations among state variables were not included in the background error covariance; additionally, some balances between analysis variables were realized by incorporating weak constraints in the cost function (Gao et al. 2004; Ge et al. 2012). Specifically, the use of the weak mass continuity constraint links the three components of wind field provided by the 3DVAR method in response to the assimilation of the radial velocity observations, and the use of the ARPS model derived equation constraint couples the other model variables and ensures the analysis variables are in balance with each other (Ge et al. 2012). The spatial correlation is modeled by a recursive filter proposed by Purser et al. (2003). A method for directly assimilating reflectivity with hydrometeor classification was proposed recently for this scheme (Gao and Stensrud 2012). In this method, a modified forward operator for radar reflectivity was developed that classifies the hydrometeor species based on the background temperature from NWP model output.

The WoF-AFS simply couples the above two systems using the so-called alpha control method initially proposed by Lorenc (2003). This coupling technique has been applied in synoptic- and mesoscale NWP systems by Buehner (2005), Buehner et al. (2010a,b), and Wang et al. (2008, 2013), and also been used operationally at NOAA (Kleist and Ide 2015; Wu et al. 2017). The current hybrid development is based on the hybrid 3DEnVAR system of Gao and Stensrud (2014), which was developed for convective-scale NWP. For the new development, ARPS is replaced by WRF-ARW, and the simplified EnKF system is replaced by the DART EAKF (also called NEWS-e as described above). Both components assimilate radar data, satellite retrieved cloud water path, and surface observations to perform a hybrid 15-min DA cycles with dual-resolution capability. With the current settings, one-way coupling of the two systems is performed; flow-dependent ensemble error covariances derived from the DART EAKF analysis system are incorporated in the hybrid 3DEnVAR in each DA cycle (Fig. 1). However, the analysis from the hybrid 3DEnVAR is not used to recenter the ensemble mean for the DART EAKF ensemble members. In the hybrid 3DEnVAR, the background error covariances are prescribed a weight of $50 \%$ of the ensemble covariance and static error covariance the remaining $50 \%$. Coupled with the hybrid 3DEnVAR analysis, a 180 -min deterministic forecast is launched every $30 \mathrm{~min}$ from these high-frequency dual-resolution DA cycles (Fig. 2). 


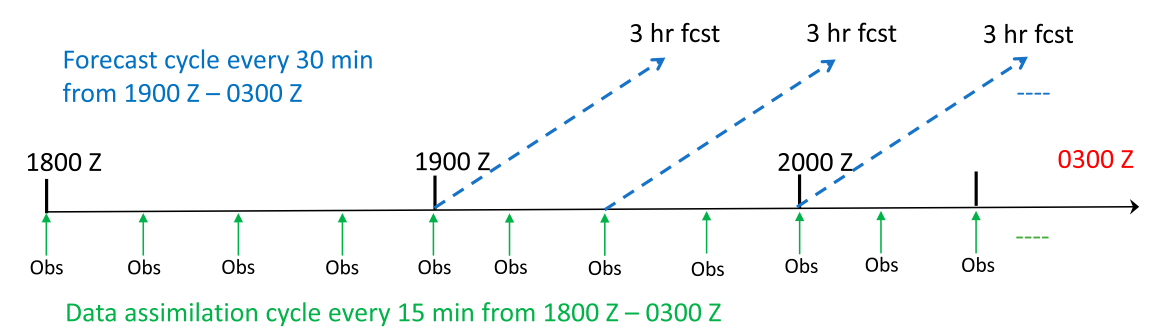

FIG. 2. Flowchart of the real-time run settings during Hazardous Weather Testbed spring experiments in 2017.

\section{Model configuration and experiment design}

The WRF-ARW model physics configuration is provided below. For both the NEWS-e ensemble forecasts and NEWS-var deterministic member forecast, the NSSL full double-moment microphysics scheme with variabledensity graupel and hail is used (Mansell et al. 2010). Other physics options for NEWS-var forecast include the Dudhia shortwave radiation scheme (Dudhia 1989), the Yonsei University (YSU; Hong et al. 2006) planetary boundary layer scheme, and the Rapid Radiative Transfer Model (RRTM) longwave radiation scheme (Mlawer et al. 1997). For NEWS-e forecast members, planetary boundary layer options include YSU, MellorYamada-Janjić (Janjić 1994), and Mellor-YamadaNakanashi-Niino (Nakanishi and Niino 2006) schemes, which are mixed with either the Dudhia and the RRTM or the Rapid Radiative Transfer Model for GCMs (RRTMG; Iacono et al. 2008) parameterizations for shortwave and longwave radiation. Full details on the NEWS-e configuration can be found in Wheatley et al. (2015) and Skinner et al. (2018).

During the 5-week HWT Spring Forecasting Experiment (HWT-SFE) 1 May-2 June 2017 (e.g., Gallo et al. 2017), the NEWS-e and NEWS-var analysis and forecast domain was $750 \mathrm{~km} \times 750 \mathrm{~km}$. For the NEWS-e component, ensemble analyses and forecast cycles were produced on $250 \times 250$ horizontal points at $3 \mathrm{~km}(\mathrm{LR})$ and 51 vertical levels. For the NEWS-var component, the single deterministic HR analyses and forecasts were produced on $500 \times 500$ horizontal points at $1.5-\mathrm{km}$ horizontal grid spacing and 51 vertical levels (Fig. 2). Analyses were produced by both components every $15 \mathrm{~min}$ between 1800 and 0300 UTC each day. The LR 36member ensemble was initialized using initial and boundary conditions provided by the High-Resolution Rapid Refresh Ensemble (HRRRE) from the Earth System Research Laboratory/Global Systems Division (ESRL/GSD), while the single deterministic HR run used initial and boundary conditions provided by the HighResolution Rapid Refresh (HRRR; Alexander et al. 2018). The observations assimilated include WSR-88D radar data, satellite derived cloud water path from GOES-13 (GOES-16 products were used beginning in 2018), and surface observations from surface aviation observations (SAO), Oklahoma mesonet, and west Texas mesonet if available. Three-hour, HR, deterministic NEWS-var forecasts were launched every half hour during the HWT-SFE period (1900-0300 UTC, Fig. 2).

Four types of sensitivity experiments are performed during the evaluation period to demonstrate the improvements made over the past several years. The control DR run (i.e., the real-time configuration in 2017, which is named CNTR_Exp) performs the NEWS-var HR $(1.5 \mathrm{~km})$ analysis and forecast using ensemble background error covariances from the LR NEWS-e forecasts. The second experiment is a single low resolution run (SLR_Exp), which performs the NEWS-var deterministic analysis and forecast at the same $3-\mathrm{km}$ horizontal grid spacing as the NEWS-e ensemble forecasts. The third experiment, named as CLD_Exp, is similar to the control DR run except that analyses of model hydrometer variables are generated using the cloud analysis method similar to that used by $\mathrm{Hu}$ et al. (2006a,b) and Schenkman et al. (2011) instead of being generated by the NEWS-var through assimilating reflectivity directly (Gao and Stensrud 2012). The mixing ratio of precipitation (including rainwater, snow, and hail), potential temperature, and water vapor mixing ratios are adjusted within the cloud analysis based on reflectivity measurements (Schenkman et al. 2011). Finally, an additional deterministic forecast is initialized from the WRF-DART ensemble mean analysis (MEAN_Exp) at $1.5-\mathrm{km}$ grid spacing to serve as a benchmark for the hybrid analyses. The performance of all four types of experiments is evaluated in the next section for three real data cases just after the convection initiation and for the forecast duration with severe weather events.

To gain an overall impression about the quality of the analyses and forecasts, the nETS and frequency bias metrics for forecast reflectivity against MRMS reflectivity over 7 (the first two cases) and 11 (the third case) 
3-h forecasts (during active thunderstorm periods for each case respectively) are first examined and compared across the four types of experiments. The nETS and bias values are computed against MRMS composite reflectivity with two different reflectivity thresholds (20 and $40 \mathrm{dBZ}$ ) during the period of greatest thunderstorm coverage for each case. Both nETS and bias values are computed with neighborhood radii between 6 and $24 \mathrm{~km}$ and similar results are reached with the different radii. For brevity, only results with a neighborhood radius of $12 \mathrm{~km}$ (i.e., using 4 grid points for $3-\mathrm{km}$ grid spacing and 8 grid points for $1.5-\mathrm{km}$ grid spacing) will be presented in the paper. A perfect analysis or forecast is defined when the nETS equals 1 , and a poor analysis and forecast are associated with nETS values close to 0 . For bias, a value of one indicates no bias, while a bias greater than (less than) 1 indicates an over (under) forecast.

The second evaluation metric will compare maximum UH tracks during the 15-min forecast outputs against the NWS local storm reports over three selected 3-h forecasts launched one hour apart. The NWS local storm reports for each event day include tornadoes, hail of 1 -in. diameter or larger, and wind gusts equal to or in excess of $50 \mathrm{kt}\left(1 \mathrm{kt} \approx 0.51 \mathrm{~m} \mathrm{~s}^{-1}\right.$ ) (or $58 \mathrm{mph}$ ). The NWS local storm reports, especially the reports for hail and tornadoes contain information about updraft rotation (Milne et al. 2018); however, reporting frequency may vary with population density and other nonmeteorological factors (e.g., Trapp et al. 2006; Potvin et al. 2019). Therefore, subjective evaluation is also performed for selected times in the 3-h forecast against composite reflectivity observations produced by MRMS.

\section{Results of experiments}

During the 5-week HWT-SFE period in 2017, there were three major severe weather outbreak periods (8-11 May; 16-19 May; 25-28 May). In this study, we chose three cases, 9 May, 16 May, and 27 May (one day from each of the above periods, respectively). The performance of the NEWS-e for severe thunderstorm analyses and forecasts in 2017, including these case studies, was reported in Skinner et al. (2018) and Jones et al. (2018). Only the results of the deterministic component of the hybrid WoF-AFS and comparisons between the four experiments are reported in this study.

\section{a. 9 May severe weather events in Texas Panhandle}

The first case examined is a tornadic supercell that occurred on 9 May 2017 over the Texas Panhandle (Fig. 3a). From 8 to 10 May, a slow moving upper low combined with rich Gulf moisture to produce several
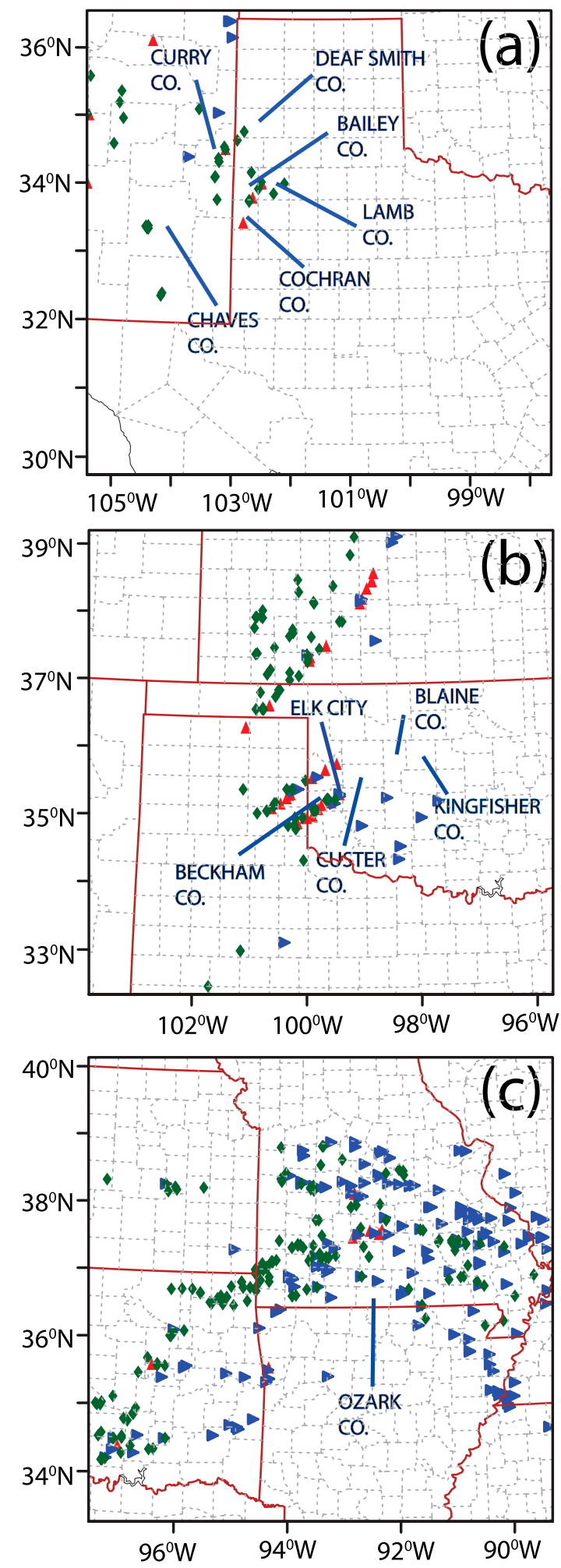

FIG. 3. The analysis and forecast domain with NWS local storm reports (red triangles for tornado reports, green rhombuses for hail reports, and blue triangles for damaging winds) for the (a) 9 May 2017 case, (b) 16 May 2017 case, and (c) 27 May 2017 case; county names mentioned in the paper are annotated specifically. 

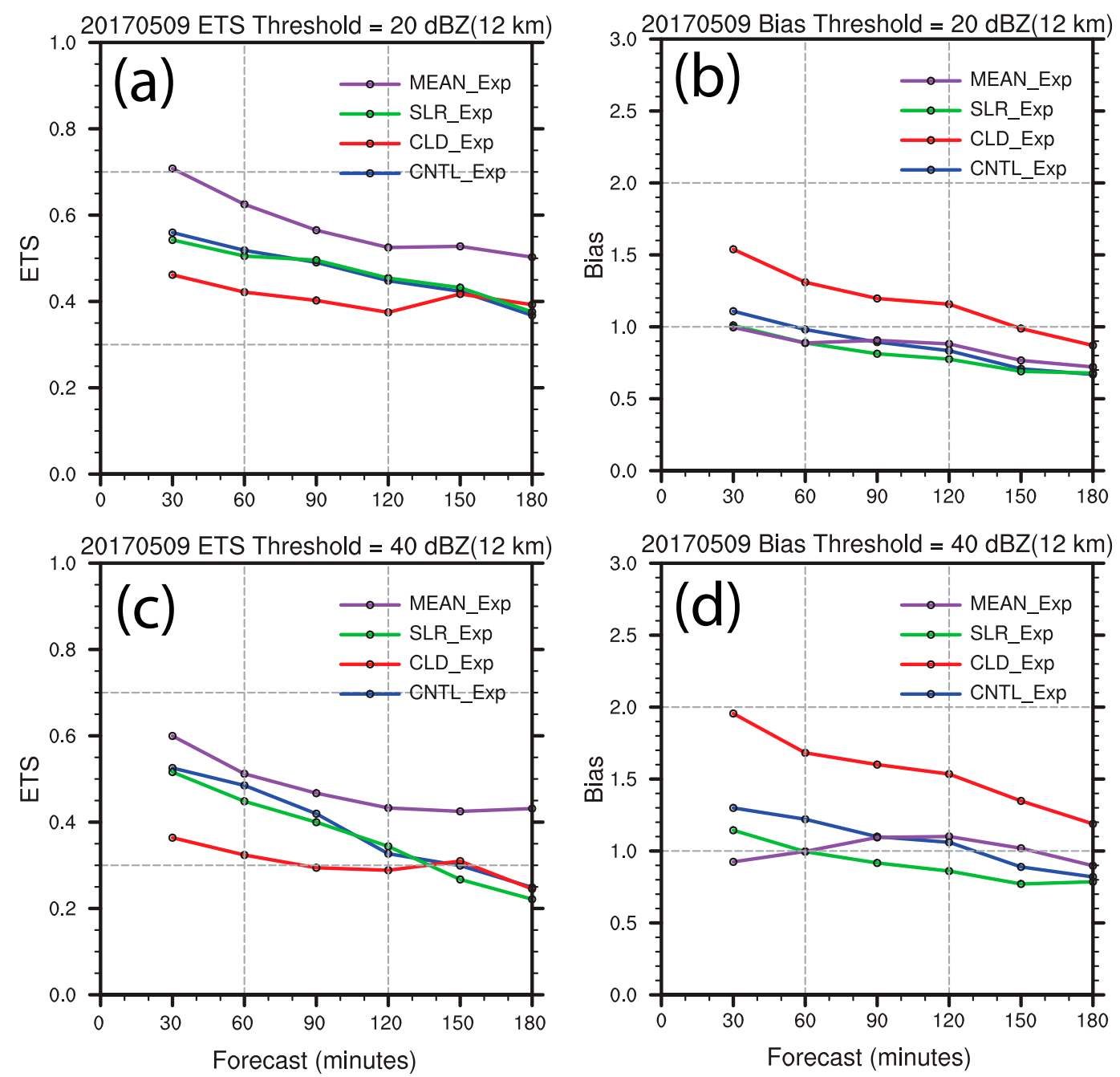

FIG. 4. The aggregated (left) nETS and (right) bias of seven 3-h free forecasts launched every half hour during the storm active period 2300 UTC 9 May-0200 UTC 10 May 2017 for composite reflectivity with a threshold of (a),(b) 20 and (c),(d) $40 \mathrm{dBZ}$ verified against the MRMS observations.

rounds of severe weather over the southern High Plains (not shown). The initial phase of severe weather occurred in eastern New Mexico during the afternoon and evening of 8 May. As the storm system moved eastward, severe thunderstorms developed in the western South Plains the evening of 9 May. Scattered supercell thunderstorms moved across the Texas Panhandle during the evening. The most intense storm tracked slowly northeastward from north Cochran County, Texas, past Sudan (west Lamb County), Texas, and produced very large hail and torrential rain along its path. It also produced two brief tornadoes, one in northeast Cochran County and another in Sudan. The largest hail reported to the NWS was tennis ball sized (2.5-in. diameter) and observed $4 \mathrm{mi}$ south of Enochs (south Bailey County), Texas. In addition, 2-4 in. of rain fell in Muleshoe (south Bailey County), Texas, within 2-3 h, causing street flooding.

The nETS values and frequency bias values of seven 3-h forecasts are computed during the period of active thunderstorms from 2300 to 0200 UTC 9 May (Fig. 4). For composite radar reflectivity fields, the MEAN_Exp produces the largest nETSs among all experiments for both reflectivity thresholds in this particular case. Both the CNTR_Exp and the SLR_Exp produce similar nETSs. This similarity suggests that the CNTR_Exp and the SLR_Exp with reflectivity assimilated in the variational framework are able to produce reasonable 3-h forecasts with generally low bias values (Figs. 4b,d). However, the biases for the 3-h forecasts in the CLD_Exp are larger (at times by a factor of 2) indicating an overprediction for reflectivity. 
To subjectively examine the impact of the DR assimilation strategy, the 2-5-km UH tracks for 3-h forecasts launched at three different times are overlaid with the NWS local storm reports during the same 3-h period (Fig. 5). The UH tracks are provided for three 0-3-h model forecasts with output every $15 \mathrm{~min}$. For the forecast launched at 2300 UTC, the CNTR_Exp (Fig. 5a) provides a more accurate prediction of mesocyclones than the other three experiments (Figs. 5d,g,j). The predicted UH tracks match quite well with the observed NWS local storm reports, especially for the two tracks with hail and tornado reports near the border of eastern New Mexico and the Texas Panhandle (Fig. 5a). The UH tracks produced by the SLR_Exp agree with the NWS local storm reports in northeast Cochran and western Lamb Counties, but not for another UH track that moves to the north of those hail reports through Curry County, New Mexico, and Deaf Smith County, Texas (Fig. 5d). Furthermore, SLR_Exp produces much smaller (almost 2 times smaller) UH values than those produced with CNTR_Exp because of the lower resolution. The UH tracks produced by MEAN_Exp capture the storm reports in Curry County, New Mexico, and Deaf Smith County in the Texas Panhandle, but misses the reports in Cochran and Bailey Counties in Texas. For the two later forecasts launched at 0000 and 0100 UTC 10 May, almost all severe hail and tornado reports are covered by the predicted UH tracks during the 3-h forecast period in the CNTR_Exp (Figs. 5b,c). However, the predicted UH tracks in other three experiments miss some severe weather events as indicated by NWS local storm reports (Figs. 5e,f,h,i,k,l). Additionally, the CLD_Exp produces spurious UH tracks in extreme northern New Mexico and the Texas Panhandle where no storms were observed.

Figure 6 shows the composite reflectivity mosaicked from the WSR-88D radars within the domain alongside predicted 3-h composite reflectivity from 0000 UTC 10 May. Although all experiments are able to predict most of the observed storms with little phase error $1 \mathrm{~h}$ into the forecast (Figs. $6 \mathrm{~d}, \mathrm{~g}$ ), almost all predicted storm cells are stronger than those observed (Fig. 6a) except for the MEAN_Exp (Fig. 6m). However, in the CLD_Exp, initial clusters of storms in eastern New Mexico grow upscale into an MCS along the border of eastern New Mexico and the Texas Panhandle (Fig. 6j). This evolution represents an erroneous prediction of the primary storm mode and, along with a spurious cluster of storms in central North Texas, is responsible for the overprediction bias in the CLD_Exp (Fig. 4).

Two hours into the forecast, the CNTR_Exp produces accurate forecasts for two supercell thunderstorms moving through Cochran and Bailey Counties of Texas (Fig. 6e). In addition to accurate predictions of the
Cochran and Bailey County supercells, the MEAN_Exp also produces good forecasts for a storm cell at the southeastern corner of Chaves County in New Mexico. The accurate prediction of the Chaves County storm likely contributes to higher nETS values for composite reflectivity in MEAN_Exp relative to the other experiments (Figs. 4a,c). The three supercells of interest are barely present in the SLR_Exp (Fig. 6h) and contain large phase errors in the CLD_Exp (Fig. 6k versus Fig. 6b).

By three hours into the forecast, the thunderstorm that produced the Morton (northeastern Cochran County) and Sudan (western Lamb County) tornadoes is well predicted (Fig. 6f versus Fig. 6c) by both CNTR_Exp and MEAN_Exp, but not by the SLR_Exp (Fig. 6i versus Fig. 6c). The CLD_Exp does a good job with the 3-h forecast of the storm, but also produces several spurious storms nearby. By this time, the CNTR_Exp, the SLR_Exp, and CLD_Exp correctly predict the cluster of storms in Chaves County, New Mexico; however, the CLD_Exp underpredicts storm intensity (Figs. 6f,i,l versus Fig. 6c), and MEAN_Exp misses the storm at this time. In general, the CNTR_Exp provides the most accurate prediction of thunderstorms across the domain for 9 May case. The MEAN_Exp produces a similarly skillful forecast; however, with smaller storm areal coverage (Figs. 6n,o versus Figs. 6b,c). Smoothing of stormscale fields in the ensemble mean likely contributes to the smaller storm size.

\section{b. 16 May tornadic supercells in northeastern Texas and southwestern Oklahoma}

On 16 May 2017, there were many severe weather events in the midwestern United States. Our analysis and forecast domain focuses on three states: Kansas, Oklahoma, and Texas (Fig. 3b), portions of which were in a moderate risk of severe storms in the Day 1 convective outlooks by the Storm Prediction Center (SPC). Most severe weather events on 16 May, especially reports of tornadoes and large hail, were located in these three states. Most of the 26 tornado reports during the forecast period were associated with two intense supercells that moved from the western Texas Panhandle through western Oklahoma. One of the long-lived supercells produced a severe damaging tornado (EF3 according to the enhanced Fujita scale with estimated wind speeds 136-165 mph) that struck Elk City, Oklahoma, killing 1 person, injuring 12 , and damaging dozens of structures.

The values of nETS and frequency bias for seven 3-h forecasts for composite reflectivity during the most active period of severe weather on 16 May (2100-0000 UTC) are computed (Fig. 7). For composite reflectivity, nETS values stay close for all experiments, especially for a 

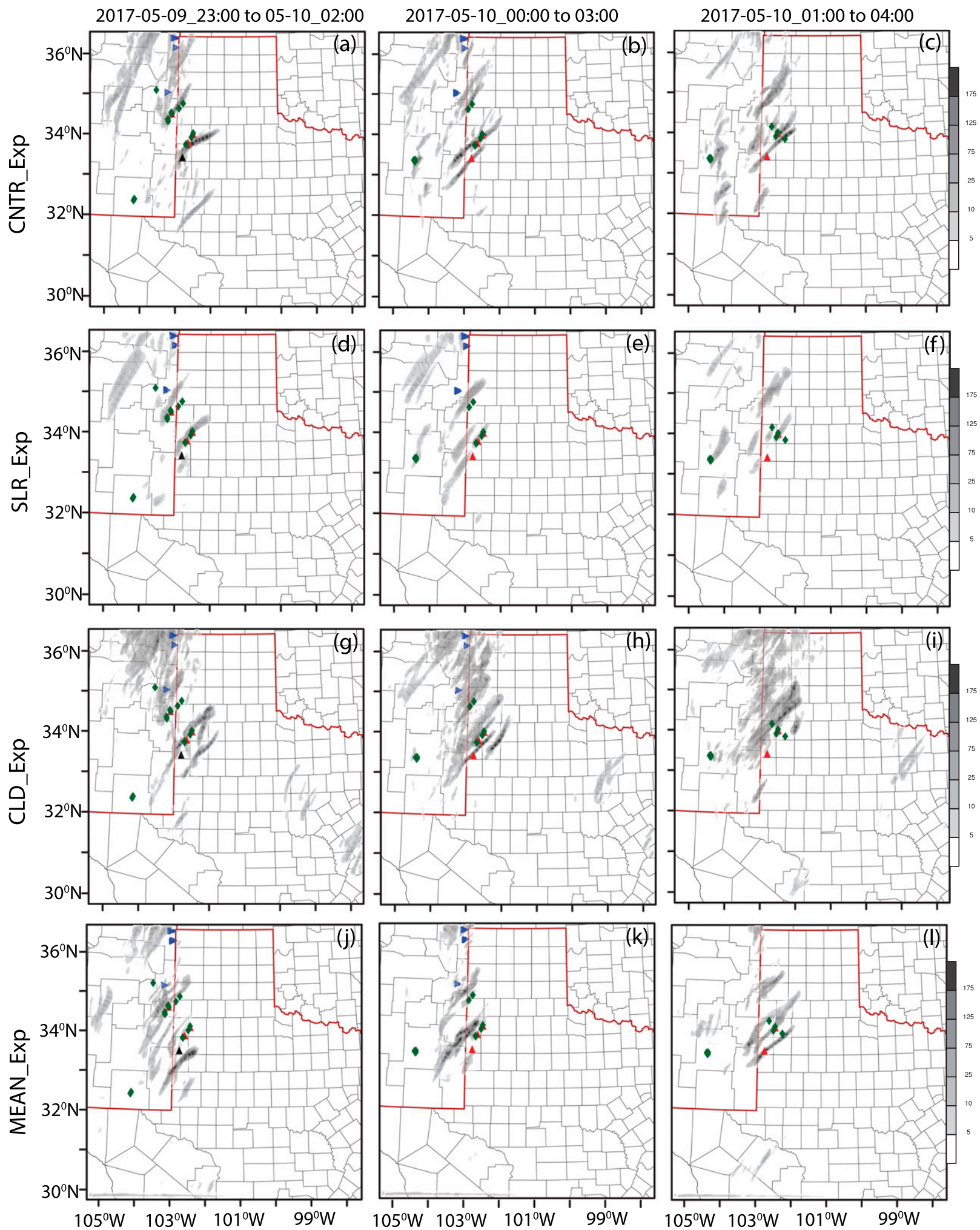

FIG. 5. The tracks of UH between 2 and $5 \mathrm{~km}$ above the ground (shaded) during the 3-h forecast period launched from (left) 2300 UTC 9 May 2017, (center) 0000 UTC 10 May 2017, and (right) 0100 UTC 10 May 2017, for (a)-(c) CNTR_Exp, (d)-(f) SLR_Exp, (g)-(i) CLD_Exp, and (j)-(l) MEAN_Exp,. NWS local storm reports at the corresponding duration are also attached (red triangles for tornado reports, green rhombuses for hail reports, and blue triangles for damaging winds). Note that the lower-resolution runs in (d)-(f) produce UH values that are 2 times smaller. 

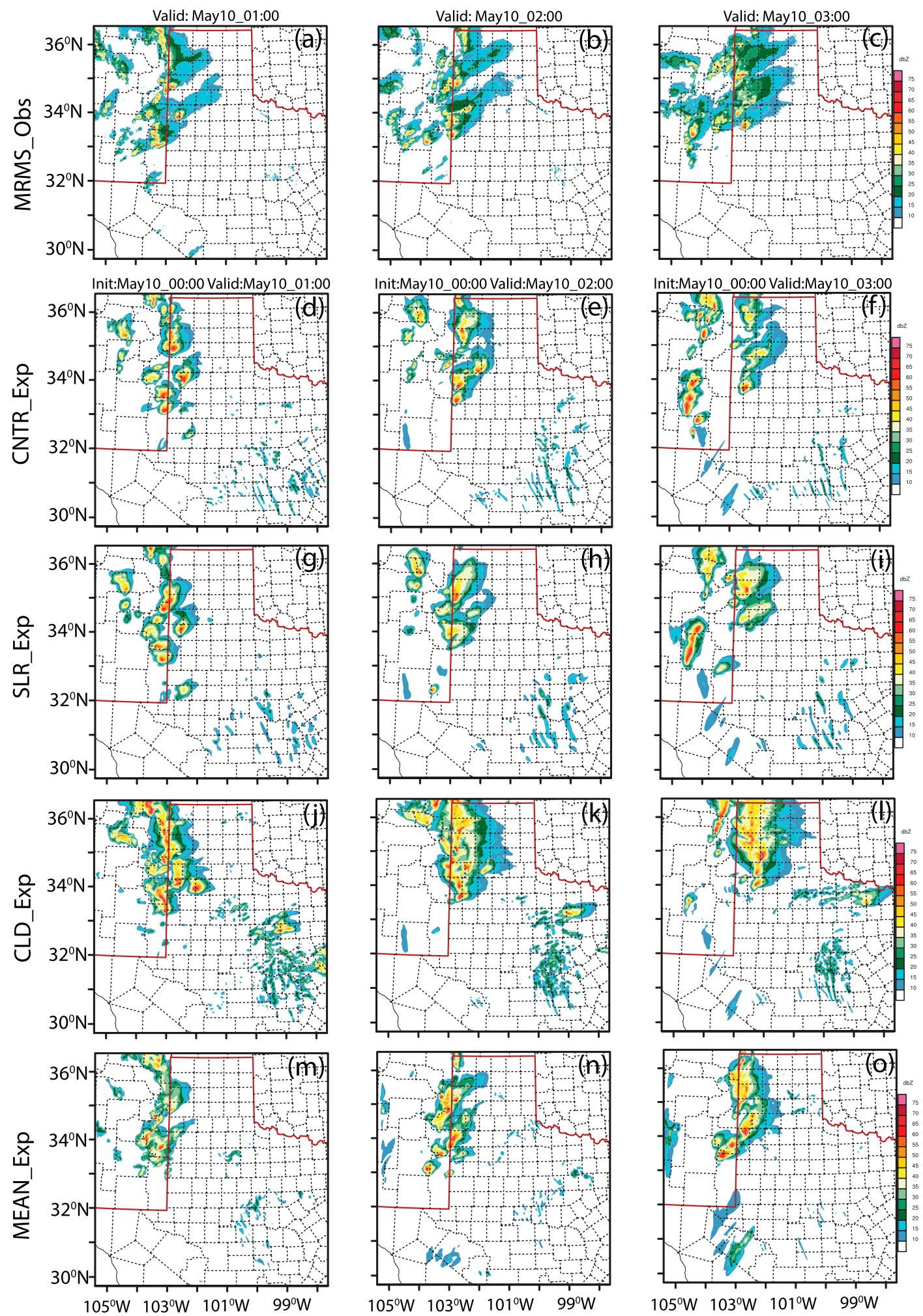

FIG. 6. (a)-(c) The composite reflectivity mosaicked from MRMS and forecasted composite reflectivity initiated at 0000 UTC 10 May 2017. The results for the forecast from (d)-(f) CNTR_Exp, (g)-(i) SLR_Exp, (j)-(1) CLD_Exp, and (m)-(o) MEAN_Exp. The (left) 1-, (center) 2-, and (right) 3-h forecast. 

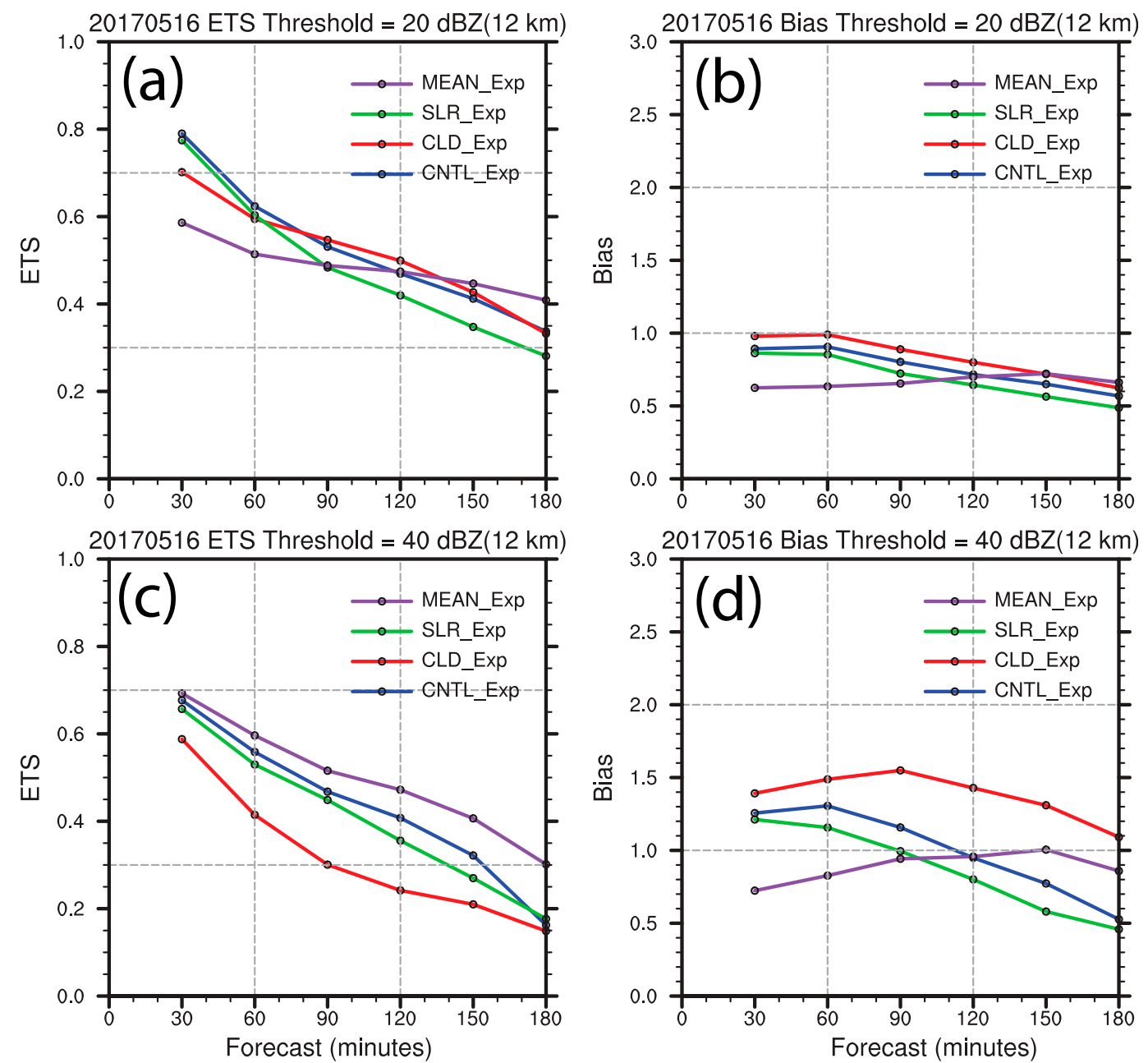

FIG. 7. As in Fig. 4, but for storm active period 2100 UTC 16 May 2017-0000 UTC 17 May 2017.

threshold of $20 \mathrm{dBZ}$ (Figs. 7a,b). The MEAN_Exp has slightly larger nETS values than other experiments for a threshold of $40 \mathrm{~dB} Z$. For bias, CNTR_Exp is smaller only than CLD_Exp up to the 120-min forecast.

The 2-5-km UH tracks for 3-h forecasts launched 16 May at 2100, 2200, and 2300 UTC, respectively, are overlaid with the NWS local storm reports to subjectively assess forecast skill for supercells. In the 2100 UTC forecast, UH tracks in the CNTR_Exp are more consistent with the NWS tornado and hail reports (Fig. 8a) than the other three experiments, especially near the Oklahoma and Texas Panhandle border (Figs. 8d,g,j versus Fig. 8a). In the 2100 UTC forecast, the UH track associated with the Elk City tornado, which occurred between 2346 and 0012 UTC, is predicted accurately by the CNTR_Exp. However, no other experiments maintain a UH track associated with the Elk City supercell through the forecast period. The forecast tracks of the two main supercells in the center of the domain continuously improve in subsequent CNTR_Exp forecasts launched at 2200 and 2300 UTC, as evidenced by the greater overlap of tornado and hail reports with predicted UH tracks (Figs. 8b,c). In contrast, both the SLR_Exp and MEAN_Exp maintain northward displacement biases in the UH tracks for the two primary supercells in forecasts launched from 2200 UTC (Figs. 8e,k). Additionally, the CLD_Exp fails to predict the UH track associated with the tornado that hit Elk City in forecasts launched from 2200 UTC (Fig. 8h). For forecasts launched from 2300 UTC, the SLR_Exp predicts UH tracks well aligned with the NWS local storm reports, but the MEAN_Exp contains large northward phase errors for UH tracks near Beckham County, Oklahoma. In all three 0-3-h forecasts, greater coverage of UH tracks is present near the northern domain boundary in the CLD_Exp, which may be attributable to the large overprediction bias in storm coverage (Figs. 7 and $8 \mathrm{~g}-\mathrm{i}$ ). 

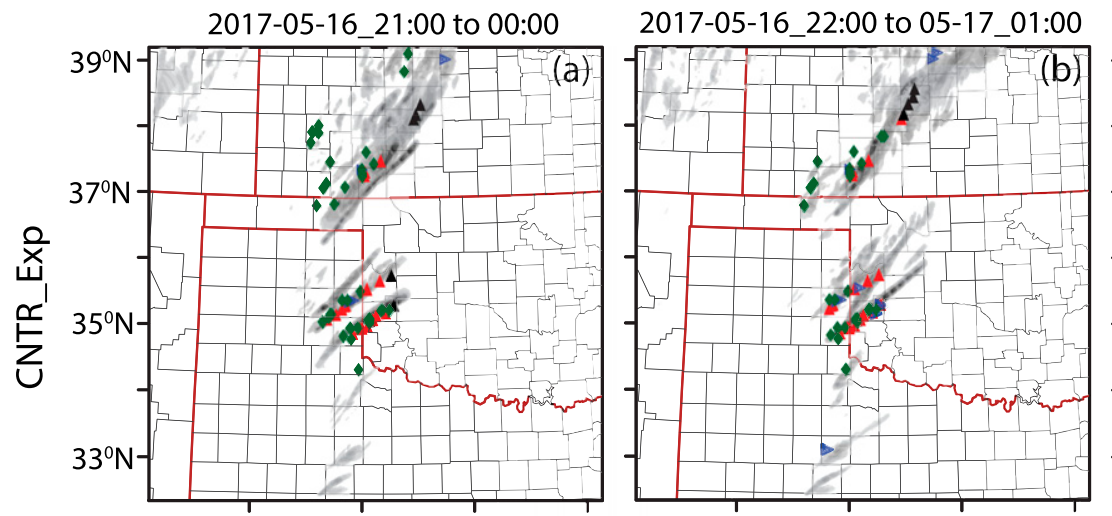

2017-05-16_23:00 to 05-17_02:00
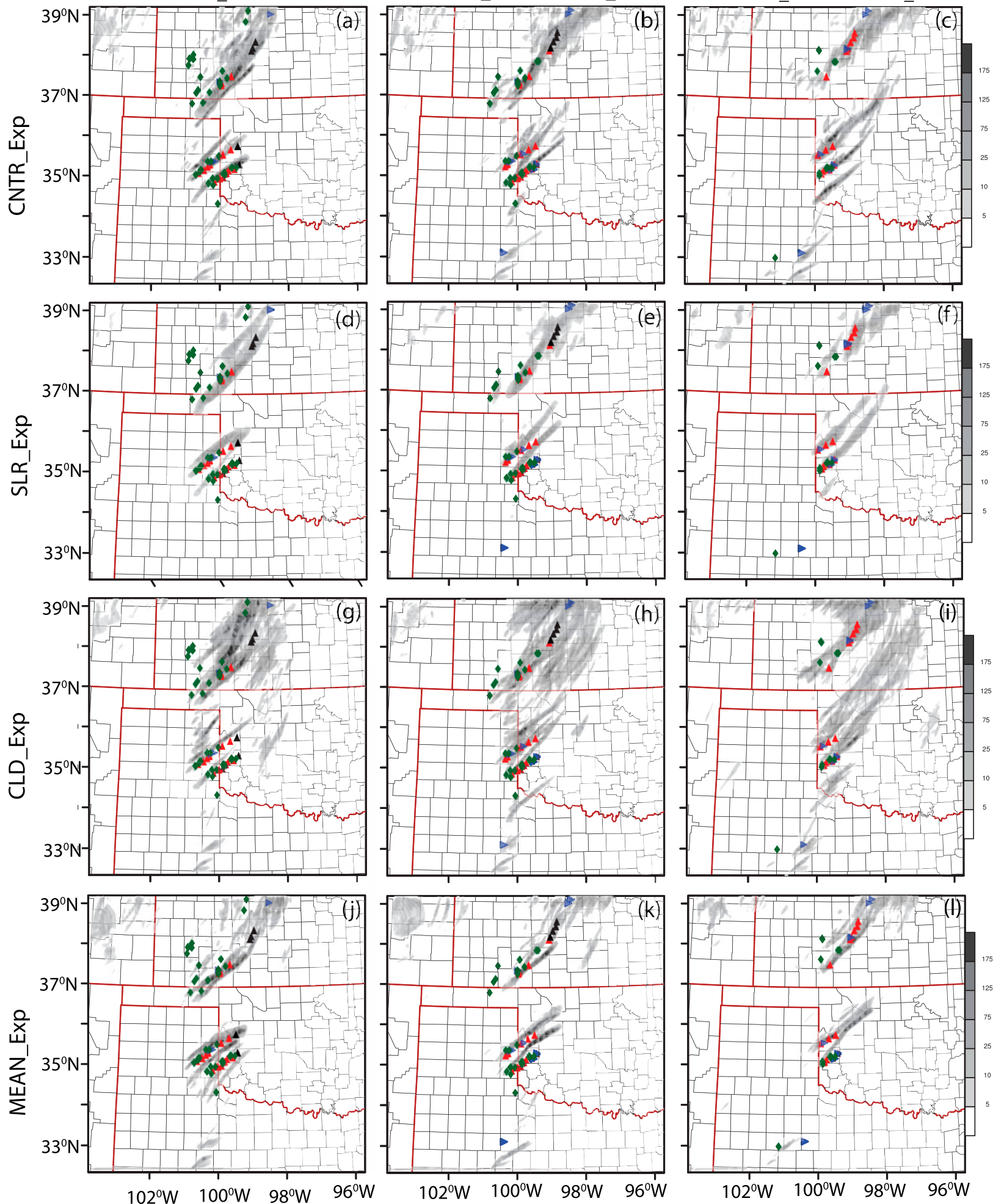

FIG. 8. As in Fig. 5, but for the Elk City, Oklahoma, tornadic thunderstorm event on 16 May 2017. The 3-h forecast period launched from (left) 2100, (center) 2200, and (right) 2300 UTC. 
As an example for a 3-h forecast, the predicted and observed MRMS composite reflectivities from over 20 NEXRAD radars over a 3 -h period beginning at 2100 UTC are compared (Fig. 9). Our discussions focus on two supercells that produced over a dozen tornadoes across the eastern Texas Panhandle and western Oklahoma. All four experiments generally capture the location of convective storms $1 \mathrm{~h}$ into the forecast. However, each experiment except the MEAN_Exp overpredicts the amplitude of composite reflectivity in individual storms compared to observations (Figs. 9a,d,g,j). However, the prediction for the southern supercell near the border of Oklahoma and Texas is very weak for MEAN_Exp (Fig. 9m). Additionally, convective coverage is generally larger for the CLD_Exp and a large, spurious cell is present in Blaine and Kingfisher Counties in central Oklahoma.

In 2-h forecasts valid at 2200 UTC, the two intense supercells near the border of Texas and Oklahoma are well predicted in the CNTR_Exp (Fig. 9e). However, only one supercell is maintained in this region in the SLR_Exp and the CLD_Exp (Figs. 9h,k). Two supercells exist near the border of Oklahoma and Texas in the MEAN_Exp, but with northward location biases (Fig. 9n). Additionally, further upscale growth of storms in southcentral Kansas predicted by the CLD_Exp is not supported by observations (Fig. 9k versus Fig. 9b). Three hours into the forecast (valid at 0000 UTC), the supercell near northeastern Beckham County and southwest Custer County in western Oklahoma is notably stronger (Fig. 9f) in the CNTR_Exp. This result is consistent with observations as the EF3 Elk City tornado was ongoing at this time. Although one supercell is also predicted at $3 \mathrm{~h}$ into the forecast (valid at 0000 UTC) in the SLR_Exp, the CLD_Exp, and the MEAN_Exp. Large northward displacement errors are present in the SLR_Exp and CLD_Exp experiments, and an overprediction bias exists in the MEAN_Exp (Fig. 9o). The potential advantages of the dual-resolution strategy with more accurate UH tracks and reflectivity forecasts are clearly demonstrated in this real data case.

\section{c. 27 May MCS in southern Missouri and northeastern Oklahoma}

The third case examined contains an MCS in southern Missouri and eastern Oklahoma on 27 May 2017 (see the domain in Fig. 3c). Several rounds of severe thunderstorms brought large hail, strong damaging winds, tornadoes, and flooding to the Missouri Ozarks, eastern Oklahoma, and southern Kansas from 27 May into the early morning hours of 28 May. Over 100 reports of severe weather and flooding were received over the region. Numerous reports of golf ball (1.75-in. diameter) and even grapefruit (4.5-in. diameter) sized hail occurred across the Missouri Ozarks, along with many reports of tree and structural damage due to straight-line winds. The MCS additionally produced flash flooding in Branson, Missouri.

For this case, the primary period of severe thunderstorm activity covered during the spring experiments was from 2000 to 0100 UTC, which is two hours longer than the period considered for the other two cases. Therefore, values for nETS and bias are aggregated across those eleven 3-h forecasts (Fig. 10). The nETSs for composite reflectivity are similar among all experiments during the first $90 \mathrm{~min}$ of forecast time, with a small improvement in the SLR_Exp and MEAN_Exp relative to the other two experiments (Figs. 10a,c). Slight improvements in nETS are seen in the CNTR_Exp over the other three experiments for both reflectivity thresholds during the latter half of the forecast period. For reflectivity, bias values stay close to 1.0 for all experiments (Figs. 10b,d). Again, these nETSs show the potential improvement in forecasts initialized with the DR variational scheme.

As with the other two cases, the quality of predicted 3-h, 2-5-km UH tracks initialized at 2200, 2300, and 0000 UTC is assessed by overlaying NWS local storm reports (Fig. 11). Most hail and damaging wind reports in the Missouri Ozarks are well predicted and overlap with strong UH values in the CNTR_Exp (Figs. 11a-c). The orientation of UH tracks match very well with the severe weather reports in the CNTR_Exp, the SLR_Exp and the MEAN_Exp. The CLD_Exp, however, predicts several UH tracks in northeastern Oklahoma and northwestern Arkansas that are not associated with observed storms.

Examination of composite reflectivity forecasts at three initialization times shows similar differences between experiments as the other two cases. The CNTR_Exp and the SLR_Exp generally predict the MCS location well relative to MRMS observations, though both predict higher reflectivity in convective cores than is observed (Figs. 12a-i). In Figs. 12j-1, the CLD_Exp looks subjectively a bit better than SLR_Exp, as the latter features a gap in the middle of the MCS that was not observed. The CLD_Exp, however, overpredicts the spatial extent of the MCS and predicts an orientation of the system that is shifted counterclockwise approximately $10^{\circ}-20^{\circ}$ from observations (Figs. $12 \mathrm{j}-1$ ). The MEAN_Exp does a good job in predicting the evolution of MCS near the border of Missouri and Arkansas, but it misses a cluster of new convection initiation in northeastern Oklahoma and southwestern Missouri at 2 and $3 \mathrm{~h}$ (Figs. 12n,o). 

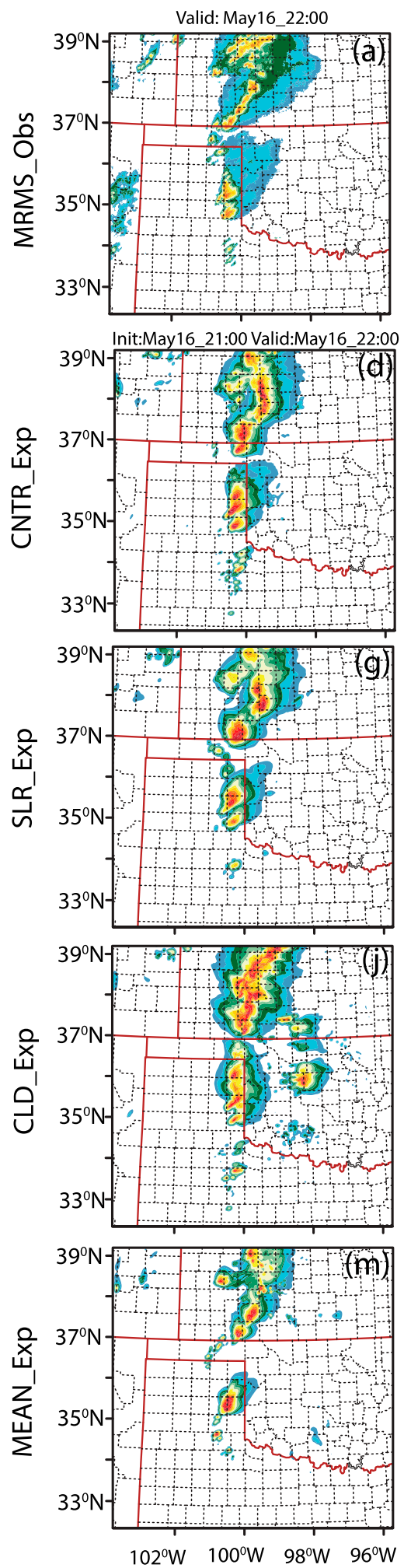
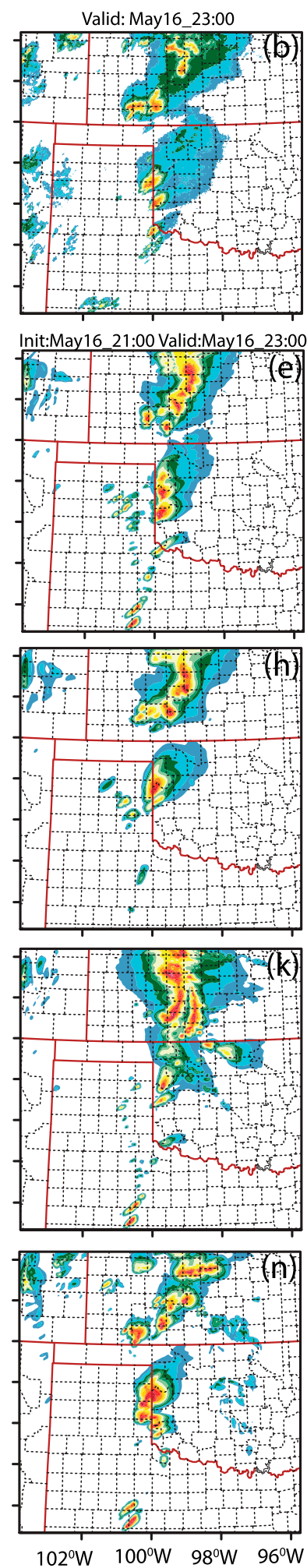
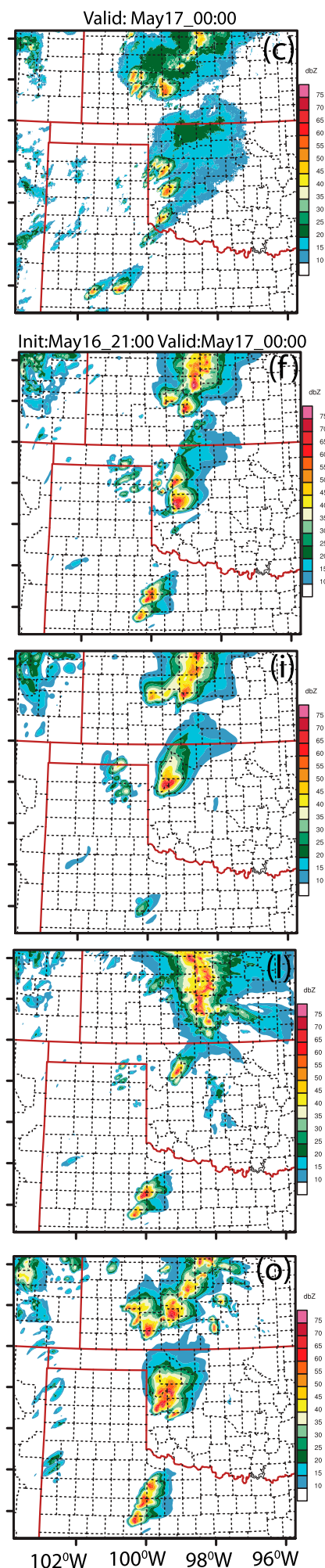

FIG. 9. As in Fig. 6, but for the Elk City, Oklahoma, tornadic thunderstorm event on 16 May 2017 launched from 2100 UTC. 

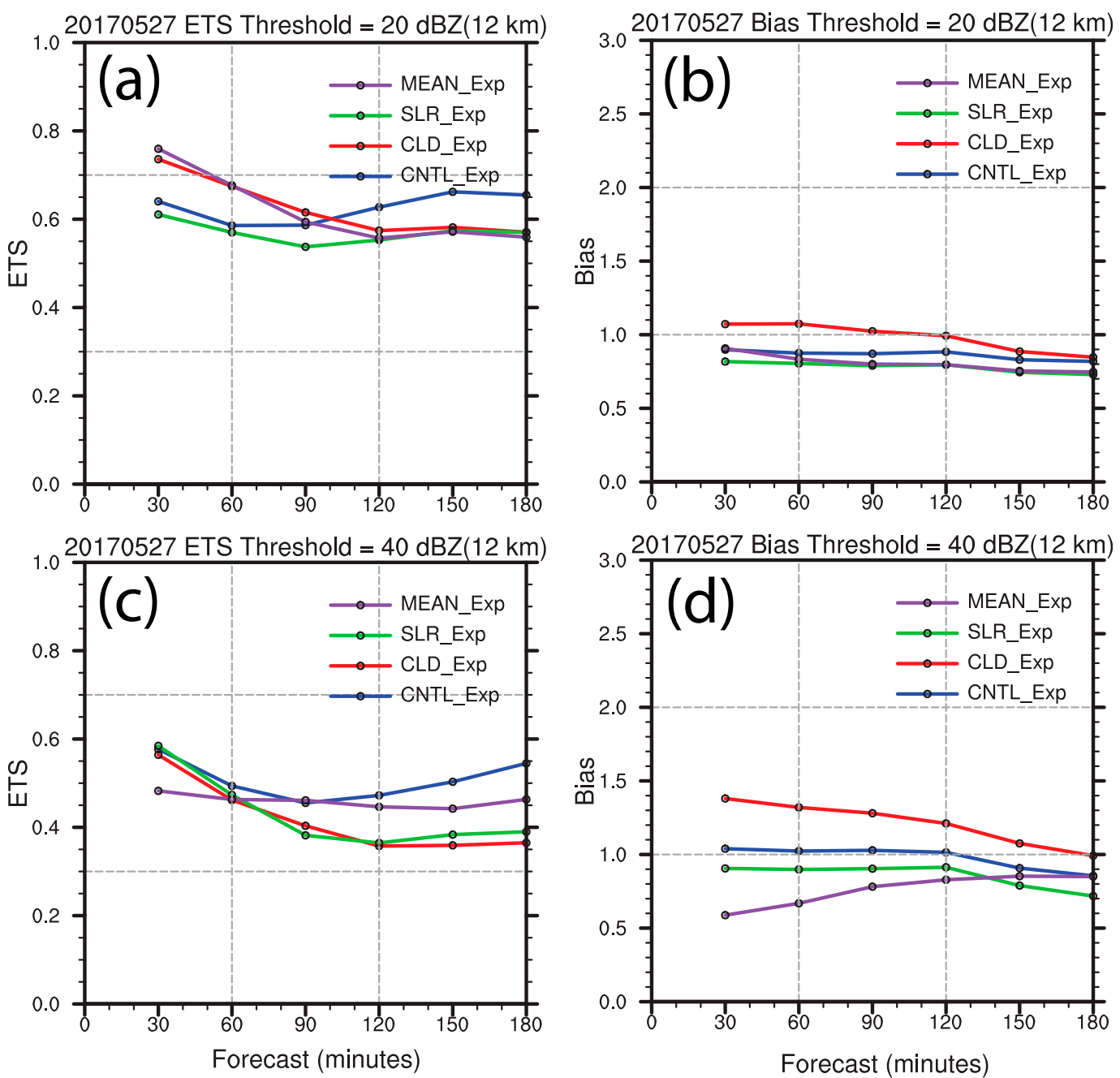

FIG. 10. As in Fig. 4, but for storm active period 2000 UTC 27 May-0100 UTC 28 May 2017.

\section{Summary and conclusions}

In this study, an experimental real-time, dual-resolution hybrid WoF-AFS with on-demand capability has been developed and tested. The system uses the WRF-ARW as its dynamic core and includes two components, the WRF-DART ensemble analysis and forecast component (NEWS-e) and a deterministic hybrid 3DEnVAR analysis and forecast component (NEWS-var). The NEWS-e component has been extensively tested in HWT spring experiments in recent years (e.g., Jones et al. 2018; Skinner et al. 2018; Wilson et al. 2019). The NEWS-var component was tested as a high-resolution analysis system for severe weather (e.g., Gao et al. 2013; Calhoun et al. 2014), but has not been extensively tested as a short-term forecast system. Both the ensemble-based and 3DVAR components of the system can incorporate available mesoscale forecasts, radar data, satellite retrieved cloud water path, and surface observations through rapid DA and forecast cycles. Each component has unique advantages and disadvantages. For example, the NEWS-e uses the WRF-DART ensemble Kalman filter system that provides flow-dependent error covariances. These flow-dependent error covariances are important for accurately analyzing small spatiotemporal scales characteristic of convective weather events. The NEWS-e employs 36 ensemble model forecasts in its 15-min DA cycles, which is computationally expensive, particularly for large model domains with high resolution. As computing resources are limited, users will have to choose between large model domains with coarse resolution or small model domains with high resolution. In contrast, the hybrid analysis system combines the ensemble covariances with the static error covariances with a weighting factor and provides one deterministic forecast of convective-scale weather at high resolution, 

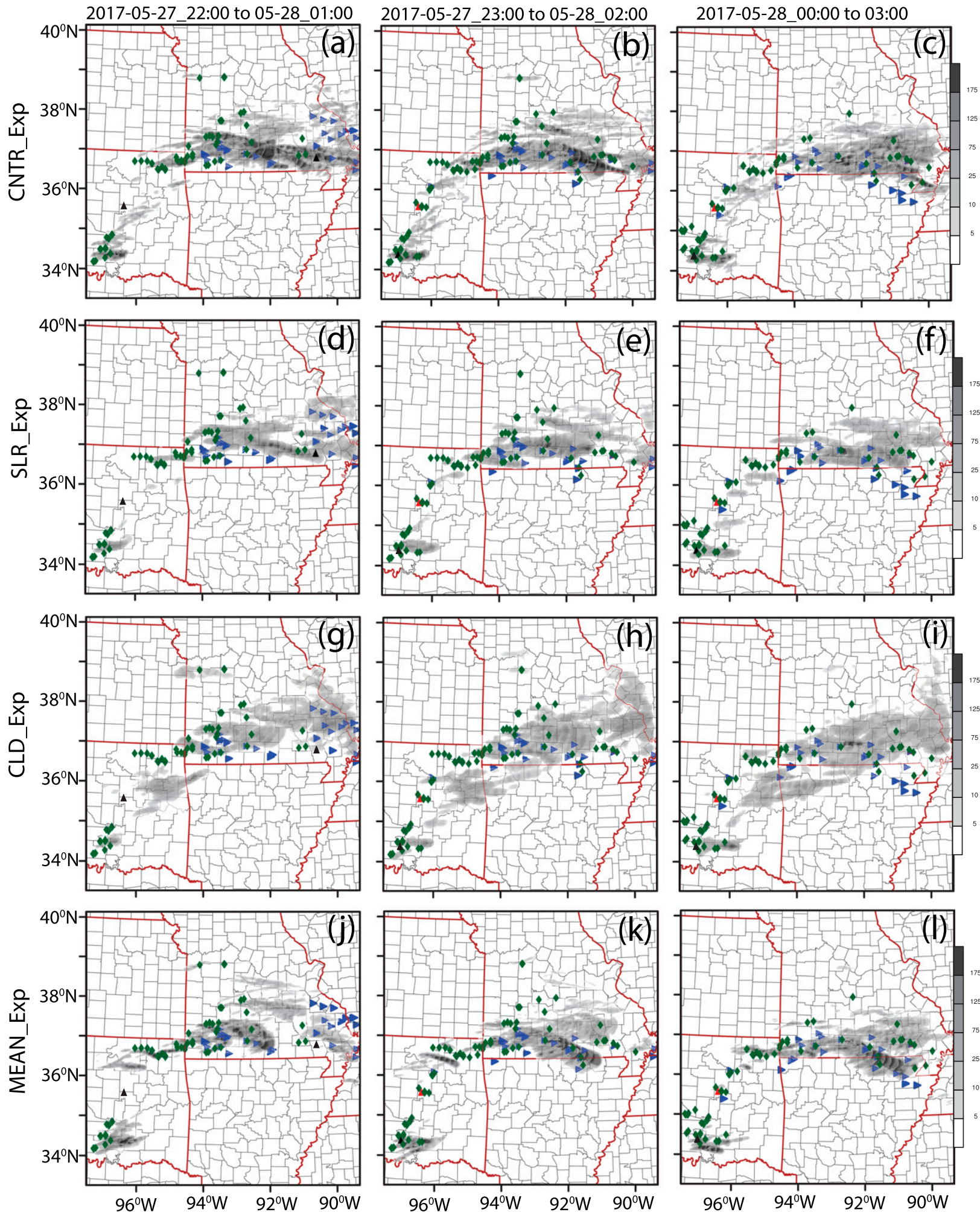

FIG. 11. As in Fig. 5, but for the event on 27 May 2017. The 3-h forecast period launched from (left) 2200 UTC 27 May, (center) 2300 UTC 27 May, and (right) 0000 UTC 28 May. 

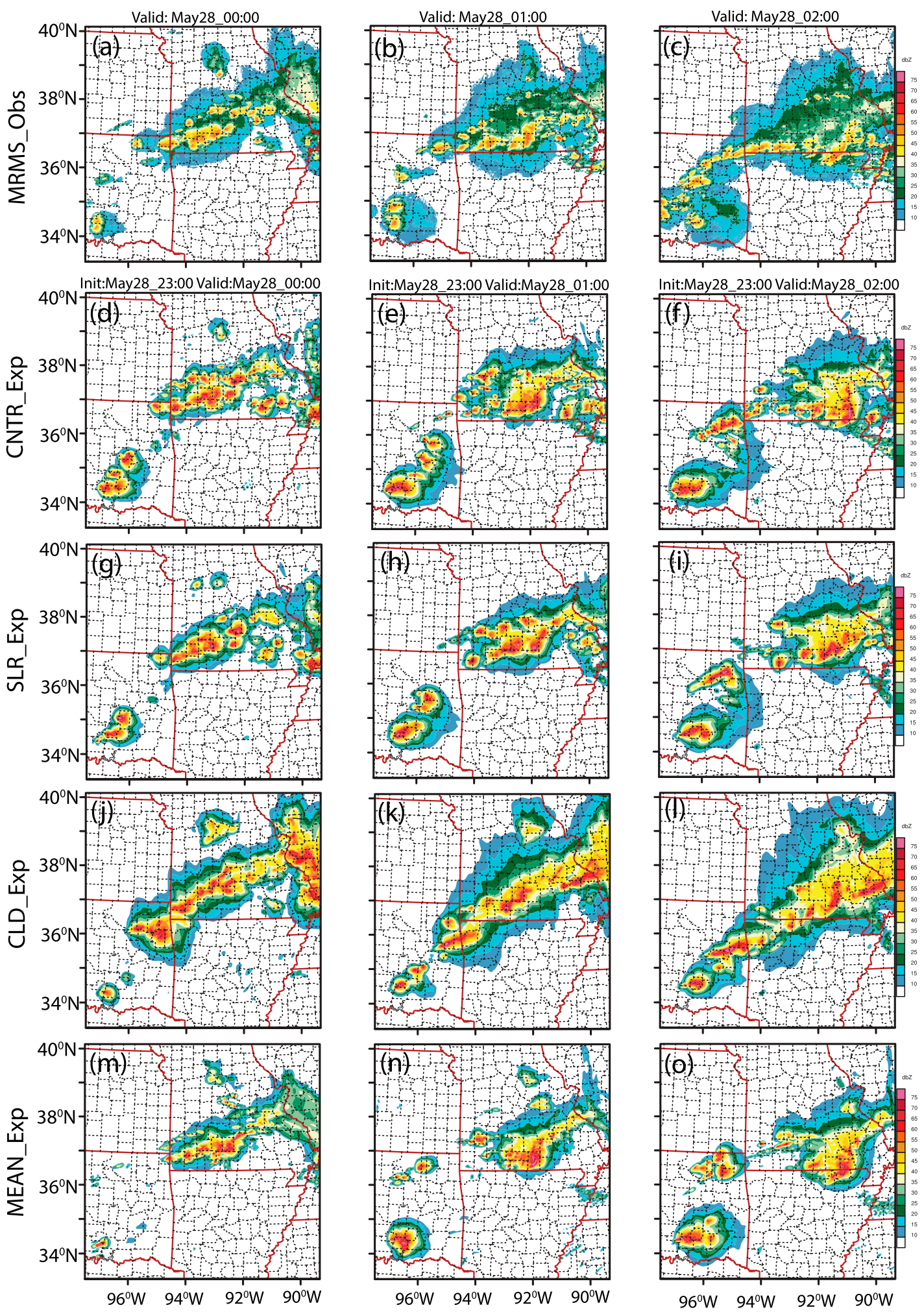

FIG. 12. As in Fig. 6, but for the case on 27 May 2017 launched from 2300 UTC. 
which is computationally more efficient. The dualresolution hybrid WoF-AFS leverages the advantages of both the ensemble components and the deterministic component, and mitigates their respective shortcomings. As a first step, one-way coupling of the two systems is performed, where ensemble covariances derived from the NEWS-e is incorporated into the NEWS-var in each DA cycle. NEWS-var background error covariances are calculated by weighting ensemble covariances as $50 \%$ of the total and static error covariances the remaining half. High-resolution, deterministic forecasts are initialized from the hybrid NEWS-var analyses.

The performance of the WoF-AFS deterministic component is evaluated with four potential configurations, DR coupling, SLR coupling, cloud analysis, and forecasts initialized from the ensemble mean for three severe weather events in 2017. The DR coupling (CNTR_Exp) forecast is initialized with the NEWS-e analysis with $3-\mathrm{km}$ grid spacing and the NEWS-var generates analyses with $1.5-\mathrm{km}$ grid spacing. The SLR coupling (SLR_Exp) is implemented with both the NEWS-e and the NEWS-var run at 3-km grid spacing. The cloud analysis option (CLD_Exp) is similar to DR coupling, except that the reflectivity observations are not assimilated through the NEWS-var directly. Instead, the model hydrometeor variables are updated with the cloud analysis scheme (Hu et al. 2006a,b; Schenkman et al. 2011). The ensemble mean forecast (MEAN_Exp) is initialized from WRF-DART ensemble analysis. Three hazardous weather events on 9 May, 16 May, and 27 May 2017 are examined in this study.

For the 9 May case, the nETSs and biases for composite reflectivity indicate the MEAN_Exp is most accurate. Subjective examination of predicted UH tracks and composite reflectivity reveals the CNTR_Exp provides the most accurate prediction of storm location and intensity relative to NWS local storm reports and MRMS composite reflectivity. The MEAN_Exp predicts storm location well, but the UH track forecasts are not as accurate as the CNTR_Exp, and the storm areas are small relative to other experiments. The smaller size of storms in the MEAN_Exp indicate storm-scale details may be excessively smoothed in the ensemble mean.

For the 16 May case, the averaged nETSs and biases for composite reflectivity from seven 3 -h forecasts shows that the performance of all experiments is close, though the MEAN_Exp and CNTL_Exp are more skillful with 40-dBZ threshold. Three 3-h forecasts launched from different times all reveal that the CNTR_Exp again predicts UH tracks that match the location of NWS local storm reports better than all other three experiments. Among 3-h forecasts from all other three experiments, the MEAN_Exp contains large displacement errors, especially for the supercell storm which produced the Elk City tornado. A specific example of the improved skill in the CNTR_Exp is found in a 3-h forecast launched from 2100 UTC, which shows the parent supercell of the EF-3 Elk City tornado is accurately predicted over two hours in advance in the deterministic forecast. In contrast, none of the other three experiments clearly maintain the Elk City supercell through the 3-h forecast period.

For the 27 May case, results show that the CLD_Exp again overpredicts storm coverage within an MCS and additionally has the largest biases and displacement errors relative to observations. Although both the CNTR_Exp and the MEAN_Exp outperform the CLD_Exp and SLR_Exp statistically, the most skillful forecast in both quantitative and subjective evaluation is provided by the CNTR_Exp.

In general, multiple 3-h forecasts launched from different times for these events demonstrate that DR strategy without using the cloud analysis performs better, qualitatively and quantitatively, than the SLR and the CLD strategies in most forecasts. Specifically, the DR experiment provides more accurate prediction of UH tracks than the other three experiments for each case considered. Although the MEAN_Exp is similarly skillful for some forecast periods, especially for the reflectivity threshold of $20 \mathrm{dBZ}$ on 9 May, the CNTR_Exp provides the most accurate guidance through the full forecast experiment for each case. In addition, deterministic experiments with forecasts launched from WRF-DART ensemble mean have been performed with both 3 - and $1.5-\mathrm{km}$ grid spacing resolution for all three cases. It is illustrated that the forecasts with $1.5-\mathrm{km}$ grid spacing generally improve over 3-km grid spacing. These extra experiments give a useful baseline, and the added value of the hybrid is more clearly demonstrated.

This study represents our initial effort to assess the use of a hybrid WoF-AFS for 0-3-h severe weather forecasts with one-way coupling. Though many scientific and technical challenges remain, we have illustrated some potential benefits provided by a DR system. The next step will be to develop two-way coupling for the hybrid WoF-AFS and test it with real-data case studies. We will also continue to conduct sensitivity tests for various system configurations to identify further performance improvements.

Besides observations used in this study, other types of observations are expected to help improve short-term, convective-scale NWP. For examples, the multilayer precipitable water contents (PW) derived from the GOES-16 satellite could help improve the near-storm environment estimation, which can result in more accurate 
prediction of storm placement and movement. Preliminary results assimilating PW data into the NEWS-var system have shown forecast improvement (Pan et al. 2018). We plan to introduce this product into the WoF-AFS and evaluate its impact on short-term convective-scale NWP with retrospective severe weather events and in real-time experiments. Future development will also focus on replacing the WRF model with the NOAA FV3 standalone regional model (Black et al. 2019). The FV3 model is NOAA's next generation unified global and regional NWP model developed by NOAA's Geophysical Fluid Dynamics Laboratory (Lin 2004). We are planning to develop interfaces for both WRF and FV3 first, then complete thorough comparisons. Our eventual goal is to help meteorologists make better forecasts for severe weather events beyond $1 \mathrm{~h}$ using convective NWP models and provide better warning information to the public, ultimately saving lives and reducing property damage.

Acknowledgments. This research was primarily funded by the NOAA Warn-on-Forecast project. The second author was partially supported by NSF Grant AGS-1341878. Additional funding was provided by NOAA/Office of Oceanic and Atmospheric Research under the NOAA-University of Oklahoma Cooperative Agreement NA08OAR4320904.

\section{REFERENCES}

Albers, S. C., J. A. McGinley, D. L. Birkenheuer, and J. R. Smart, 1996: The Local Analysis and Prediction System (LAPS): Analyses of clouds, precipitation, and temperature. Wea. Forecasting, 11, 273-287, https://doi.org/10.1175/1520-0434(1996) $011<0273$ :TLAAPS $>2.0$.CO;2.

Alexander, C. R., and Coauthors, 2018: Development of the High Resolution Rapid Refresh Ensemble (HRRRE). 22nd Conf. on Integrated Observing and Assimilation Systems for the Atmosphere, Oceans, and Land Surface, Austin, TX, Amer. Meteor. Soc., 11.3, https://ams.confex.com/ams/98Annual/ webprogram/Paper335526.html.

Anderson, J. L., 2001: An ensemble adjustment filter for DA. Mon. Wea. Rev., 129, 2884-2903, https://doi.org/10.1175/1520-0493(2001) 129<2884:AEAKFF>2.0.CO;2.

—, and N. Collins, 2007: Scalable implementations of ensemble filter algorithms for data assimilation. J. Atmos. Oceanic Technol., 24, 1452-1463, https://doi.org/10.1175/JTECH2049.1.

—, T. Hoar, K. Raeder, H. Liu, N. Collins, R. Torn, and A. Avellano, 2009: The Data Assimilation Research Testbed: A community facility. Bull. Amer. Meteor. Soc., 90, 1283-1296, https://doi.org/10.1175/2009BAMS2618.1.

Barker, D. M., and Coauthors, 2012: The Weather Research and Forecasting Model's community variational/ensemble DA system: WRFDA. Bull. Amer. Meteor. Soc., 93, 831-843, https:// doi.org/10.1175/BAMS-D-11-00167.1.

Black, T. L., J. A. Abeles, B. T. Blake, D. Jovic, E. Rogers, Y. Lin, L. C. Dawson, and J. R. Carley, 2019: A standalone limited area capability for the finite-volume cubed-sphere dynamic core. 2019 WGNE Bluebook, 2 pp., http://bluebook.meteoinfo.ru/ uploads/2019/docs/05_Black_Thomas_FV3regional.pdf.

Brewster, K., M. Hu, M. Xue, and J. Gao, 2005: Efficient assimilation of radar data at high resolution for shortrange numerical weather prediction. World Weather Research Program Symposium on Nowcasting and Very Short-Range Forecasting, WSN05, Tolouse, France, WMO, Paper 3.06.

Buehner, M., 2005: Ensemble-derived stationary and flowdependent background-error covariances: Evaluation in a quasi-operational NWP setting. Quart. J. Roy. Meteor. Soc., 131, 1013-1043, https://doi.org/10.1256/qj.04.15.

P. L. Houtekamer, C. Charette, H. L. Mitchell, and B. He, 2010a: Intercomparison of variational DA and the ensemble Kalman filter for global deterministic NWP. Part I: Description and single-observation experiments. Mon. Wea. Rev., 138, 1550-1566, https://doi.org/10.1175/2009MWR3157.1.

,,,,---- and,$- 2010 \mathrm{~b}$ : Intercomparison of variational DA and the ensemble Kalman filter for global deterministic NWP. Part II: One-month experiments with real observations. Mon. Wea. Rev., 138, 1567-1586, https://doi.org/ 10.1175/2009MWR3158.1.

Calhoun, K. M., T. M. Smith, D. M. Kingfield, J. Gao, and D. J. Stensrud, 2014: Forecaster use and evaluation of real-time 3DVAR analyses during severe thunderstorm and tornado warning operations in the Hazardous Weather Testbed. Wea. Forecasting, 29, 601-613, https://doi.org/10.1175/ WAF-D-13-00107.1.

Clark, A. J., W. A. Gallus Jr., and M. L. Weisman, 2010: Neighborhood-based verification of precipitation forecasts from convection-allowing NCAR WRF model simulations and the operational NAM. Wea. Forecasting, 25, 1495-1509, https:// doi.org/10.1175/2010WAF2222404.1.

Dudhia, J., 1989: Numerical study of convection observed during the Winter Monsoon Experiment using a mesoscale twodimensional model. J. Atmos. Sci., 46, 3077-3107, https:// doi.org/10.1175/1520-0469(1989)046<3077:NSOCOD> 2.0.CO;2.

Fujita, T., 2010: Development of an ensemble DA system for mesoscale ensemble prediction. Fourth EnKF Workshop, Rensselaerville, NY.

Gallo, B. T., and Coauthors, 2017: Breaking new ground in severe weather prediction: The 2015 NOAA/Hazardous Weather Testbed spring forecasting experiment. Wea. Forecasting, 32, 1541-1568, https://doi.org/10.1175/WAFD-16-0178.1.

Gao, J., and D. Stensrud, 2012: Assimilation of reflectivity data in a convective-scale, cycled 3DVAR framework with hydrometeor classification. J. Atmos. Sci., 69, 1054-1065, https://doi.org/10.1175/JAS-D-11-0162.1.

, and - 2014: Some observing system simulation experiments with a hybrid 3DEnVAR system for stormscale radar DA. Mon. Wea. Rev., 142, 3326-3346, https://doi.org/10.1175/ MWR-D-14-00025.1.

—, and M. Xue, 2008: An efficient dual-resolution approach for ensemble DA and tests with assimilated Doppler radar data. Mon. Wea. Rev., 136, 945-963, https://doi.org/10.1175/ 2007MWR2120.1.

__, —_, A. Shapiro, and K. K. Droegemeier, 1999: A variational method for the retrieval of three-dimensional wind fields from dual-Doppler radars. Mon. Wea. Rev., 127, 2128-2142, https://doi.org/10.1175/1520-0493(1999) 127<2128:AVMFTA $>2.0 . \mathrm{CO} ; 2$. 
- — - K. Brewster, F. Carr, and K. K. Droegemeier, 2002: New development of a 3DVAR system for a nonhydrostatic NWP model. Preprint, 15th Conf. on Numerical Weather Prediction/19th Conf. on Weather Analysis and Forecasting, San Antonio, TX, Amer. Meteor. Soc., 339-341. , and K. K. Droegemeier, 2004: A three-dimensional variational DA method with recursive filter for single-Doppler radar. J. Atmos. Oceanic Technol., 21, 457-469, https://doi.org/ 10.1175/1520-0426(2004)021<0457:ATVDAM>2.0.CO;2.

— , and Coauthors, 2013: A real-time weather-adaptive 3DVAR analysis system for severe weather detections and warnings with automatic storm positioning capability. Wea. Forecasting, 28, 727-745, https://doi.org/10.1175/WAF-D-12-00093.1.

—, C. Fu, D. J. Stensrud, and J. S. Kain, 2016: OSSEs for an ensemble 3DVAR data assimilation system with radar observations of convective storms. J. Atmos. Sci., 73, 2403-2426, https://doi.org/10.1175/JAS-D-15-0311.1.

Ge, G., J. Gao, K. A. Brewster, and M. Xue, 2010: Effects of beam broadening and earth curvature in radar DA. J. Atmos. Oceanic Technol., 27, 617-636, https://doi.org/10.1175/2009JTECHA1359.1.

,$- \ldots$, and M. Xue, 2012: Diagnostic pressure equation as a weak constraint in a storm-scale three-dimensional variational radar data assimilation system. J. Atmos. Oceanic Technol., 29, 1075-1092, https://doi.org/10.1175/JTECH-D-11-00201.1.

Gilbert, G. K., 1884: Finley's tornado predictions. Amer. Meteor. J., 1, 166-172.

Hong, S.-Y., Y. Noh, and J. Dudhia, 2006: A new vertical diffusion package with an explicit treatment of entrainment processes. Mon. Wea. Rev., 134, 2318-2341, https://doi.org/10.1175/ MWR3199.1.

Hu, M., M. Xue, and K. Brewster, 2006a: 3DVAR and cloud analysis with WSR-88D Level-II data for the prediction of the Fort Worth, Texas, tornadic thunderstorms. Part I: Cloud analysis and its impact. Mon. Wea. Rev., 134, 675-698, https:// doi.org/10.1175/MWR3092.1.

,$- \ldots$ J. Gao, and K. Brewster, 2006b: 3DVAR and cloud analysis with WSR-88D Level-II data for the prediction of the Fort Worth, Texas, tornadic thunderstorms. Part II: Impact of radial velocity analysis via 3DVAR. Mon. Wea. Rev., 134, 699-721, https://doi.org/10.1175/MWR3093.1.

Iacono, M. J., J. S. Delamere, E. J. Mlawer, M. W. Shephard, S. A. Clough, and W. D. Collins, 2008: Radiative forcing by long-lived greenhouse gases: Calculations with the AER radiative transfer models. J. Geophys. Res., 113, D13103, https://doi.org/10.1029/2008JD009944.

Janjić, Z. I., 1994: The step-mountain Eta coordinate model: Further developments of the convection, viscous sublayer, and turbulence closure schemes. Mon. Wea. Rev., 122, 927-945, https://doi.org/10.1175/1520-0493(1994) 122<0927:TSMECM >2.0.CO;2.

_ - T. L. Black, E. Rogers, H. Chuang, and G. DiMego, 2003: The NCEP nonhydrostatic mesoscale forecasting model. Preprints, 10th Conf. on Mesoscale Processes, Portland, OR, Amer. Meteor. Soc., 12.1, https://ams.confex.com/ams/10Meso/ webprogram/Paper62675.html.

Jones, T. A., D. J. Stensrud, P. Minnis, and R. Palikonda, 2013: Evaluation of a forward operator to assimilate cloud water path into WRF-DART. Mon. Wea. Rev., 141, 2272-2289, https://doi.org/10.1175/MWR-D-12-00238.1.

, J. A. Otkin, D. J. Stensrud, and K. Knopfmeier, 2014: Forecast evaluation of an observing system simulation experiment assimilating both radar and satellite data. Mon. Wea. Rev., 142, 107-124, https://doi.org/10.1175/MWR-D-13-00151.1.
, K. Knopfmeier, D. M. Wheatley, G. Creager, P. Minnis, and R. Palikonda, 2016: Storm-scale DA and ensemble forecasting with the NSSL experimental Warn-on-Forecast System. Part II: Combined radar and satellite data experiments. Wea. Forecasting, 31, 297-327, https://doi.org/ 10.1175/WAF-D-15-0107.1.

— , P. Skinner, K. Knopfmeier, E. Mansell, P. Minnis, R. Palikonda, and W. J. Smith, 2018: Comparison of cloud microphysics schemes in a Warn-on-Forecast system using synthetic satellite objects. Wea. Forecasting, 33, 1681-1708, https://doi.org/10.1175/WAF-D-18-0112.1.

Kain, J. S., and Coauthors, 2008: Some practical considerations regarding horizontal resolution in the first generation of operational convection-allowing NWP. Wea. Forecasting, 23, 931-952, https://doi.org/10.1175/WAF2007106.1.

_ from high-resolution forecast models: Monitoring selected fields and phenomena every time step. Wea. Forecasting, 25, 1536-1542, https://doi.org/10.1175/2010WAF2222430.1.

Kleist, D. T., and K. Ide, 2015: An OSSE-based evaluation of hybrid variational-ensemble data assimilation for the NCEP GFS. Part II: 4DEnVar and hybrid variants. Mon. Wea. Rev., 143, 452-470, https://doi.org/10.1175/MWR-D-13-00350.1.

Kong, R., M. Xue, and C. Liu, 2018: Development of a hybrid En3Dvar data assimilation system and comparisons with 3Dvar and EnKF for radar data assimilation with observing system simulation experiments. Mon. Wea. Rev., 146, 175-198, https://doi.org/10.1175/MWR-D-17-0164.1.

Lin, S., 2004: A “vertically Lagrangian" finite-volume dynamical core for global models. Mon. Wea. Rev., 132, 2293-2307, https://doi.org/10.1175/1520-0493(2004)132<2293:AVLFDC> 2.0.CO;2.

Lorenc, A., 2003: The potential of the ensemble Kalman filter for NWP-A comparison with 4Dvar. Quart. J. Roy. Meteor. Soc., 129, 3183-3204, https://doi.org/10.1256/qj.02.132.

Mansell, E. R., C. L. Ziegler, and E. C. Bruning, 2010: Simulated electrification of a small thunderstorm with two-moment bulk microphysics. J. Atmos. Sci., 67, 171-194, https://doi.org/ 10.1175/2009JAS2965.1.

Milne, J. M., I. L. Jirak, and H. E. Brooks, 2018: Investigating the vertical structure of updraft helicity in convection-allowing models. 29th Conf. on Severe Local Storms, Stowe, VT, Amer. Meteor. Soc., 154, https://ams.confex.com/ams/29SLS/ webprogram/Paper348472.html.

Mlawer, E. J., S. J. Taubman, P. D. Brown, M. J. Iacono, and S. A. Clough, 1997: Radiative transfer for inhomogeneous atmospheres: RRTM, a validated correlated-k model for the longwave. J. Geophys. Res., 102, 16 663-16 682, https://doi.org/ 10.1029/97JD00237.

Nakanishi, M., and H. Niino, 2006: An improved Mellor-Yamada level-3 model: Its numerical stability and application to a regional prediction of advection fog. Bound.-Layer Meteor., 119, 397-407, https://doi.org/10.1007/s10546-005-9030-8.

Pan, S., J. Gao, D. J. Stensrud, X. Wang, and T. A. Jones, 2018: Assimilation of radar radial velocity and reflectivity, satellite cloud water path and total precipitable water for convective scale NWP in OSSEs. J. Atmos. Oceanic Technol., 35, 67-89, https://doi.org/10.1175/JTECH-D-17-0081.1.

Potvin, C. K., C. Broyles, P. S. Skinner, H. E. Brooks, and E. Rasmussen, 2019: A Bayesian hierarchical modeling framework for correcting reporting bias in the U.S. tornado database. Wea. Forecasting, 34, 15-30, https://doi.org/10.1175/ WAF-D-18-0137.1. 
Pu, Z., S. Zhang, M. Tong, and V. Tallapragada, 2016: Influence of the self-consistent regional ensemble background error covariance on hurricane inner-core data assimilation with the GSI-based hybrid system for HWRF. J. Atmos. Sci., 73, 4911-4925, https://doi.org/10.1175/ JAS-D-16-0017.1.

Purser, R. J., W.-S. Wu, D. Parrish, and N. M. Roberts, 2003: Numerical aspects of the application of recursive filters to variational statistical analysis. Part I: Spatially homogeneous and isotropic Gaussian covariances. Mon. Wea. Rev., 131, 1524-1535, https://doi.org/10.1175//1520-0493(2003) $131<1524:$ NAOTAO $>2.0 . \mathrm{CO} ; 2$.

Schenkman, A., M. Xue, A. Shapiro, K. Brewster, and J. Gao, 2011: The analysis and prediction of the 8-9 May 2007 Oklahoma tornadic mesoscale convective system by assimilating WSR-88D and CASA radar data using 3DVAR. Mon. Wea. Rev., 139, 224-246, https://doi.org/10.1175/ 2010MWR3336.1.

Skamarock, W. C., and Coauthors, 2008: description of the Advanced Research WRF version 3. NCAR Tech. Note NCAR/TN-475+STR, 113 pp., https://doi.org/10.5065/ D68S4MVH.

Skinner, P. S., and Coauthors, 2018: Object-based verification of a prototype Warn-on-Forecast system. Wea. Forecasting, 33, 1225-1250, https://doi.org/10.1175/WAF-D-18-0020.1.

Smith, T. M., and Coauthors, 2016: Multi-Radar Multi-Sensor (MRMS) severe weather and aviation products: Initial operating capabilities. Bull. Amer. Meteor. Soc., 97, 1617-1630, https://doi.org/10.1175/BAMS-D-14-00173.1.

__ , and Coauthors, 2014: Performance of a real-time 3DVAR analysis system in the Hazardous Weather Testbed. Wea. Forecasting, 29, 63-77, https://doi.org/10.1175/WAF-D13-00044.1.

Stensrud, D. J., and J. Gao, 2010: Importance of horizontally inhomogeneous environmental initial conditions to ensemble storm-scale radar data assimilation and very short-range forecasts. Mon. Wea. Rev., 138, 1250-1272, https://doi.org/ 10.1175/2009MWR3027.1.

— , and Coauthors, 2009: Convective-scale warn on forecast: A vision for 2020. Bull. Amer. Meteor. Soc., 90, 1487-1499, https:// doi.org/10.1175/2009BAMS2795.1.

_ - and Coauthors, 2013: Progress and challenges with warnon-forecast. Atmos. Res., 123, 2-16, https://doi.org/10.1016/ j.atmosres.2012.04.004.

Trapp, R. J., D. M. Wheatley, N. T. Atkins, R. W. Przybylinski, and R. Wolf, 2006: Buyer beware: Some words of caution on the use of severe wind reports in postevent assessment and research. Wea. Forecasting, 21, 408-415, https://doi.org/10.1175/ WAF925.1.

Wang, X., D. M. Barker, C. Snyder, and T. M. Hamill, 2008: A hybrid ETKF-3DVAR DA scheme for the WRF Model. Part I: Observing system simulation experiment. Mon. Wea. Rev., 136, 5116-5131, https://doi.org/ 10.1175/2008MWR2444.1.

—, D. Parrish, D. Kleist, and J. Whitaker, 2013: GSI 3Dvarbased ensemble-variational hybrid DA for NCEP Global Forecast System: Single-resolution experiments. Mon. Wea. Rev., 141, 4098-4117, https://doi.org/10.1175/MWR-D12-00141.1.

Wang, Y., and X. Wang, 2017: Direct assimilation of radar reflectivity without tangent linear and adjoint of the nonlinear observation operator in the GSI-based EnVar system: Methodology and experiment with the 8 May 2003 Oklahoma City tornadic supercell. Mon. Wea. Rev., 145, 1447-1471, https:// doi.org/10.1175/MWR-D-16-0231.1.

, J. Gao, P. S. Skinner, K. Knopfmeirer, T. Jones, P. L. Heiselman, and L. J. Wicker, 2018: Test of a weather-adaptive dual-resolution hybrid 3DEnVAR and WRF-DART analysis and forecast system for severe weather events. 22nd Conf. on Integrated $\mathrm{Ob}$ serving and Assimilation Systems for the Atmosphere, Oceans, and Land Surface (IOAS-AOLS), Austin, TX, Amer. Meteor. Soc., 168, https://ams.confex.com/ams/98Annual/webprogram/ Paper330920.html.

Wheatley, D. M., and D. J. Stensrud, 2010: The impact of assimilating surface pressure observations on severe weather events in a WRF mesoscale ensemble system. Mon. Wea. Rev., 138, 1673-1694, https://doi.org/10.1175/ 2009MWR3042.1.

— K. H. Knopfmeier, T. A. Jones, and G. J. Creager, 2015: Storm-scale DA and ensemble forecasting with the NSSL Experimental Warn-on-Forecast System. Part I: Radar data experiments. Wea. Forecasting, 30, 1795-1817, https://doi.org/ 10.1175/WAF-D-15-0043.1.

Wilson, K. A., P. L. Heinselman, P. S. Skinner, J. J. Choate, and K. E. Klockow-McClean, 2019: Meteorologists' interpretations of storm-scale ensemble-based forecast guidance. Wea. Climate Soc., 11, 337-354, https://doi.org/10.1175/WCAS-D18-0084.1.

Wu, W., D. F. Parrish, E. Rogers, and Y. Lin, 2017: Regional ensemble-variational data assimilation using global ensemble forecasts. Wea. Forecasting, 32, 83-96, https://doi.org/10.1175/ WAF-D-16-0045.1.

Xue, M., K. K. Droegemeier, and V. Wong, 2000: The Advanced Regional Prediction System (ARPS)-A multiscale nonhydrostatic atmospheric simulation and prediction model. Part I: Model dynamics and verification. Meteor. Atmos. Phys., 75, 161-193, https://doi.org/10.1007/ s007030070003.

tion System (ARPS) - A multiscale nonhydrostatic atmospheric simulation and prediction tool. Part II: Model physics and applications. Meteor. Atmos. Phys., 76, 143-165, https://doi.org/10.1007/s007030170027.

- - , D. Wang, J. Gao, K. Brewster, and K. K. Droegemeier, 2003: The Advanced Regional Prediction System (ARPS), storm-scale numerical weather prediction and data assimilation. Meteor. Atmos. Phys., 82, 139-170, 10.1007/ s00703-001-0595-6.

Yang, S.-C., E. Kalnay, B. Hunt, and N. E. Bowler, 2009: Weight interpolation for efficient data assimilation with the Local Ensemble Transform Kalman Filter. Quart. J. Roy. Meteor. Soc., 135, 251-262, https://doi.org/10.1002/ qj.353.

Yussouf, N., D. C. Dowell, L. J. Wicker, K. H. Knopfmeier, and D. M. Wheatley, 2015: Storm-scale data assimilation and ensemble forecasts for the 27 April 2011 severe weather outbreak in Alabama. Mon. Wea. Rev., 143, 3044-3066, https://doi.org/ 10.1175/MWR-D-14-00268.1.

Zhang, F., M. Zhang, and J. Poterjoy, 2013: E3Dvar: Coupling an ensemble Kalman filter with three-dimensional variational DA in a limited-area weather prediction model and comparison to E4Dvar. Mon. Wea. Rev., 141, 900-917, https://doi.org/ 10.1175/MWR-D-12-00075.1.

Zhang, J., F. Carr, and K. Brewster, 1998: ADAS cloud analysis. Preprints, 12th Conf. on Numerical Weather Prediction, Phoenix, AZ., Amer. Meteor. Soc., 185-188. 